Article

\title{
Stereoscopic Height and Wind Retrievals for Aerosol Plumes with the MISR INteractive eXplorer (MINX)
}

\author{
David L. Nelson ${ }^{1, *}$, Michael J. Garay ${ }^{2}$, Ralph A. Kahn ${ }^{3}$ and Ben A. Dunst ${ }^{4}$ \\ 1 Raytheon Company, Pasadena, CA 91101, USA \\ 2 Jet Propulsion Laboratory, California Institute of Technology, Pasadena, CA 91109, USA; \\ E-Mail: Michael.J.Garay@jpl.nasa.gov \\ 3 NASA Goddard Space Flight Center, Greenbelt, MD 20771, USA; E-Mail: Ralph.Kahn@ nasa.gov \\ 4 Mechanical and Aerospace Engineering Department, University of California, Los Angeles, \\ Los Angeles, CA 90095, USA; E-Mail: bendunst@ucla.edu \\ * Author to whom correspondence should be addressed; E-Mail: David.L.Nelson@jpl.nasa.gov; \\ Tel.: +1-818-393-7641; Fax: +1-818-393-4619.
}

Received: 5 August 2013; in revised form: 7 September 2013 / Accepted: 10 September 2013 / Published: 17 September 2013

\begin{abstract}
The Multi-angle Imaging SpectroRadiometer (MISR) instrument aboard the Terra satellite acquires imagery at $275-\mathrm{m}$ resolution at nine angles ranging from $0^{\circ}$ (nadir) to $70^{\circ}$ off-nadir. This multi-angle capability facilitates the stereoscopic retrieval of heights and motion vectors for clouds and aerosol plumes. MISR's operational stereo product uses this capability to retrieve cloud heights and winds for every satellite orbit, yielding global coverage every nine days. The MISR INteractive eXplorer (MINX) visualization and analysis tool complements the operational stereo product by providing users the ability to retrieve heights and winds locally for detailed studies of smoke, dust and volcanic ash plumes, as well as clouds, at higher spatial resolution and with greater precision than is possible with the operational product or with other space-based, passive, remote sensing instruments. This ability to investigate plume geometry and dynamics is becoming increasingly important as climate and air quality studies require greater knowledge about the injection of aerosols and the location of clouds within the atmosphere. MINX incorporates features that allow users to customize their stereo retrievals for optimum results under varying aerosol and underlying surface conditions. This paper discusses the stereo retrieval algorithms and retrieval options in MINX, and provides appropriate examples to explain how the program can be used to achieve the best results.
\end{abstract}


Keywords: aerosol sensing; MINX; MISR; plume height; stereoscopic retrieval

\section{Introduction}

Wildfire smoke, desert dust, and volcanic ash aerosols can have significant effects on climate [1-3]. They can also threaten public health and safety $[4,5]$. These aerosols typically originate as plumes that are lofted from relatively small source regions and are transported varying distances downwind. Observation and modeling of plume rise and transport are important to climate and air quality studies because aerosols that rise into the free atmosphere can remain aloft longer and be transported farther than those that remain within the planetary boundary layer [6,7]. The altitude of absorbing aerosols is particularly significant in determining atmospheric heating rates, and surface deposition of such particles can increase rates of melting of ice and snow [8-10].

Multi-image satellite stereoscopic height retrievals for clouds date from the early days of satellite remote sensing in the late 1960's and early 1970's [11]. The Multi-angle Imaging SpectroRadiometer (MISR), that flies aboard the NASA Earth Observing System Terra satellite, was developed specifically to take advantage of this approach for extracting information about cloud and aerosol plume heights [12,13]. The basic method and operational implementation are described in detail elsewhere [14-17], and are briefly summarized in Section 2.2 below. Among the space-based, passive, aerosol-and-cloud-height retrieval techniques demonstrated to date, the stereo imaging approach has the advantages of being solely geometric, so that retrieved heights are independent of radiometric calibration uncertainties and detailed knowledge of the atmospheric temperature structure, and it provides close spatial sampling defined by the image swath, which for MISR amounts to global coverage about once per week. The primary limitations of MISR's stereo imaging approach are the need to observe well-defined aerosol features that are identifiable between multi-angle camera views and that are optically dense enough to obscure underlying terrain and the need to determine the direction of aerosol transport before accurate heights can be retrieved.

Unlike the stereo retrieval technique employed by MISR, space-based lidars such as the Cloud-Aerosol Lidar with Orthogonal Polarization (CALIOP) instrument [18] can retrieve the altitude of sub-visible and homogenous aerosols and clouds and, in the absence of significant attenuation, provide vertical structure information, identifying higher, thinner layers of opacity in the atmosphere [19]. However, because of attenuation, lidars are unable to obtain information below optically thick layers, and spatial sampling from space-based lidars is limited to a narrow "curtain" which is about 90 m wide for CALIOP, so specific targets such as aerosol source regions are rarely observed. As such, the stereo imaging and lidar techniques are complementary for aerosol research, with stereo imaging constraining aerosol near-source regions, and space-based lidar capturing optically thinner yet more extensive downwind layers [6].

A third suite of satellite height retrieval techniques, devoted primarily to clouds, uses thermal infrared spectral bands to determine effective cloud-top temperature and/or pressure [20]. Instruments such as the Moderate Resolution Imaging Spectroradiometer (MODIS) and the Geostationary Operational Environmental Satellite (GOES) imagers, that have the required thermal bands, provide frequent, near-global retrievals of cloud-top heights. However, these techniques rely upon good radiometric 
calibration, and require constraints or assumptions about cloud emissivity, surface temperature, and atmospheric temperature and water vapor profiles, all of which contribute to the uncertainties of these techniques.

To complement the operational stereo height and wind product from MISR, a stereoscopic height retrieval algorithm was developed to retrieve height and motion-vector information at the highest spatial resolution possible with the MISR data, focusing specifically on aerosol plumes. This work is an extension of a data-mining project associating MISR smoke plume heights with fire hot-spot measurements from the MODIS instrument, also on the Terra satellite [21]. The new algorithm was incorporated into an interactive software tool named the MISR INteractive eXplorer (MINX). Several papers have been published that use the results of MINX smoke plume height retrievals [6,7,22-26], and a public database of MINX plume retrievals has been made available online [27].

Recently the use of MINX has been extended to the retrieval of heights and winds for volcanic ash and dust plumes [28-32] and to the study of hurricanes and boundary layer clouds. In addition, experience with different aerosol types and different surface conditions has motivated the development of a new version of the MINX software that contains a greater variety of customizable height retrieval options compared with earlier versions. This paper describes the methodology used in the MINX retrievals, illustrates some of the options available for obtaining high-quality plume heights and motion-vectors, and presents example results for a range of natural situations.

It is beyond the scope of the current paper to present new validation data for MINX-derived MISR stereo heights, which will be the focus of subsequent work. However, the operational MISR stereo retrievals have been validated by extensive comparisons with coincident ground-based lidar and radar observations over both land and ocean [33-36]. The results of these studies indicate that for optically thick clouds the operational MISR stereo product (Version 17) with a spatial resolution of $1.1 \mathrm{~km} \times 1.1 \mathrm{~km}$ and a vertical resolution quantized at $560 \mathrm{~m}$ agrees with the ground-based observations within better than a kilometer.

For the purposes of this paper, an aerosol "plume" is defined as a region of optically distinct aerosol that resides above and downwind of an identified source, and which typically has discernable edges and a visible connection to the source, so that the direction of aerosol transport can be determined visually. In this case a "wind-corrected" height, that distinguishes feature displacements between different MISR camera views due to stereo parallax from those due to plume advection, is computed. If the direction of transport cannot be determined, the algorithm assumes all feature motion as viewed from camera to camera is due solely to parallax, and the target aerosol is termed an aerosol "cloud." In this case the so-called "zero-wind" height is reported. Subsequent references either to height retrievals or to height plus wind retrievals may use the general term "stereo retrievals."

\section{MISR}

\subsection{Instrument}

The MISR instrument flies aboard Terra, the flagship satellite in NASA's Earth Observing System (EOS) fleet. Terra is in a near-polar orbit at an altitude of $705 \mathrm{~km}$, descending on the dayside with an equator crossing of 10:30 am local time, and completes an orbit in about 99 min. Each circuit of the Earth falls into one of 233 overlapping "paths" which repeat precisely every 16 days. Since Terra's 
launch in December 1999, data have been acquired for nearly 73,000 orbits. Enough fuel remains for operations until at least 2018.

MISR has a unique design for imaging the Earth, using nine push-broom cameras designated Df, Cf, $\mathrm{Bf}$, Af, An, Aa, Ba, Ca, and Da, where An is the nadir-viewing camera and the letters " $\mathrm{f}$ " and " $\mathrm{a}$ " refer to forward-viewing and aft-viewing, respectively. The camera viewing angles relative to nadir are $70.5^{\circ}(\mathrm{D}), 60.0^{\circ}(\mathrm{C}), 45.6^{\circ}(\mathrm{B})$, and $26.1^{\circ}(\mathrm{A})$. This design allows the instrument to image every scene at nine viewing zenith angles in line with the ground track of the satellite, in seven minutes. The width of the MISR swath common to all cameras is about $380 \mathrm{~km}$, providing global coverage every nine days at the equator and every two days near the poles [37].

Radiance data are acquired in four spectral bands in each camera. The central wavelengths and effective bandpasses are $446.4 \pm 41.9 \mathrm{~nm}$ for blue; $557.5 \pm 28.6 \mathrm{~nm}$ for green; $671.7 \pm 21.9 \mathrm{~nm}$ for red; and $866.4 \pm 39.7 \mathrm{~nm}$ for NIR. The radiances are mapped to the Space Oblique Mercator (SOM) projection so that ground sample spacing is $275 \mathrm{~m}$ in 12 of MISR's 36 channels (in the red band of all nine cameras and in all four bands of the nadir camera) and at $1100 \mathrm{~m}$ in the remaining 24 channels. More information about the MISR instrument can be found in [12,37].

\subsection{Data Products}

Raw MISR data are processed and stored at the NASA Langley Atmospheric Science Data Center. Available datasets include Level 1 radiance and geometric products, Level 2 aerosol and cloud products, Level 3 globally gridded statistical summaries, and ancillary datasets generated once and used in routine processing [38]. Level 1 and 2 (swath) datasets are divided into 180 "blocks" per orbit, with each block spanning $140.8 \mathrm{~km}$ along-track. Typically about 144 of these blocks are populated with data, their positions in the swath varying with season so they occupy northernmost positions on 21 June and southernmost positions on 21 December. All MISR products are written in HDF format and are freely downloadable [39]. A description of the algorithms for data product generation can be found in [40], and data product specifications for the HDF files can be found in [41]. Because Level 1 radiance products are central to the stereo retrieval process, they are described in greater detail next. A brief description of the operational stereo product is also included to provide a basis for comparison with MINX stereo retrievals.

Two sets of Level 1 radiometrically- and geometrically-calibrated data products are produced for every MISR orbit. Ellipsoid-referenced imagery (GRP_ELLIPSOID) projects the radiances to the surface ellipsoid, which corresponds closely to mean sea level [12,42]. For this data set, features above ellipsoid level, such as clouds and mountains, appear to move when viewed at different camera angles because of parallax. Terrain-referenced imagery (GRP_TERRAIN) is projected to a digital elevation model (DEM) $[12,42]$. In this projection, mountains and other features on the Earth's surface appear fixed in position when successive camera images are viewed. However, elevated clouds and aerosol plumes still appear to move between camera images. In the along-track direction (the direction parallel to the ground-track of the satellite), this motion is a combination of apparent motion due to parallax and real motion due to wind [14,15]. In the across-track direction (normal to the along-track direction or right-left across an image), motion relative to the surface is due only to wind. In cameras with more oblique viewing angles, gaps are sometimes visible in terrain-referenced images as a result of line-of-sight occlusions caused by steep terrain. 
The stereo retrieval algorithms in the operational MISR L2 cloud products and in MINX utilize the multiple views acquired by MISR to compute the heights and motion-vectors of clouds and other features above the Earth's surface using a purely geometric, stereoscopic method [16]. The operational stereo product retrieves cloud-top heights and winds automatically for every orbit using ellipsoid-referenced imagery to produce a dataset appropriate for studying global statistics of cloud heights and winds. Consequently, the underlying algorithms must be very fast and use a fixed set of processing parameters that are applied to all scenes equally [17]. Because they are automatic, the operational algorithms lack the advantage of interactivity and human-in-the-loop analysis by which features can be isolated for special study, and the operational algorithms cannot take advantage of visual cues in a scene from which wind direction can be inferred. Instead, both the along-track and across-track components of the wind speed are first derived at relatively coarse spatial resolution in order to mitigate the effects of noise [43]. These results are then applied to initial (zero-wind) retrievals of cloud-top height to produce wind-corrected heights at $1.1 \mathrm{~km}$ horizontal resolution. To extract wind direction and the along-track component of wind speed requires well-registered $\mathrm{Df} / \mathrm{Da}\left( \pm 70^{\circ}\right)$ and $\mathrm{Bf} / \mathrm{Ba}\left( \pm 46^{\circ}\right)$ camera imagery [43]. Including the most oblique (D) cameras is an essential element of the automatic retrieval strategy, because only these views can take advantage of earth curvature to resolve wind speed [14,15]. These requirements sacrifice some of the redundancy available in MISR's multi-camera design.

\section{MINX}

\subsection{History}

MISR's operational stereo product does not generally retrieve heights and winds with the precision and fine resolution required for detailed study of small aerosol features such as smoke or volcanic plumes. In order to effectively utilize the redundant, multi-angle, stereoscopic capabilities of MISR, the MINX interactive visualization application was developed to complement the operational stereo product by providing users a tool to retrieve height and wind information interactively with both the wind and height reported at high spatial resolution and enhanced precision. MINX is written in the Interactive Data Language (IDL) [44]. It enables a user to explore the structure and dynamics of aerosol features having visible structure in multi-angle images by iterating on stereo retrievals using different combinations of wind direction and other parameters. The MINX program can be downloaded from the Open Channel Foundation website [45] and is available for Mac OS X, MS Windows, and Linux platforms. Since 2006, MINX has been used under the auspices of the MISR Plume Height Climatology Project (MPHCP), aimed at creating an aerosol injection height climatology to support wildfire, climate change, and air quality studies [21]. To date, about 13,000 smoke plumes have been digitized from selected parts of the 13-year MISR data record, and retrieved heights, winds, and other information have been compiled into a publicly accessible, online database [27]. NASA and the US Environmental Protection Agency (EPA) supplied original funding for the project.

\subsection{Data Requirements}

MINX requires all nine camera files of terrain-referenced imagery (GRP_TERRAIN) to derive accurate heights and winds over land [42]. For aerosols over open ocean, ellipsoid-referenced imagery 
(GRP_ELLIPSOID) must be used. This is because the DEM and the ellipsoid are identical over the ocean and terrain-referenced imagery is not available for analysis. An additional MISR Level 1 data product is needed for MINX stereo retrievals. The geometric parameters product (GP_GMP) contains zenith and azimuth viewing angles for each camera at $17.6 \mathrm{~km}$ resolution, but they are interpolated to $275 \mathrm{~m}$ during stereo retrievals. This geometry is essential for modeling ray-paths from the surface to the satellite. The MISR Ancillary Geographic Product (AGP) is one further product MINX requires to perform stereo retrievals. This dataset contains the Digital Elevation Model (DEM) and surface feature IDs that include land/water identifiers. These data are stored at $1.1 \mathrm{~km}$ spatial resolution, and a single file is available for each of the 233 different MISR paths.

MINX does not require MISR Level 2 products for retrieving heights. However, three products can optionally be loaded and displayed. Optical depths and other parameters from the aerosol product (AS_AEROSOL) can be displayed as histograms for a digitized region, and smoke, dust, cloud, and land masks from the Support Vector Machine (SVM) datasets [46] in the cloud classifiers product (TC_CLASSIFIERS) can be overlain on radiance imagery to assist in identifying aerosol types. Finally, stereo heights and winds from MISR's operational stereo products (the older TC_STEREO and newer TC_CLOUD) can be compared with MINX retrieval results on height/wind profile plots.

\subsection{The MINX GUI}

MINX presents the user with a graphical user interface (GUI) that includes a large viewing window in which the nine camera images from a portion of an orbit can be displayed in an animation loop using play/pause movie controls. This animation capability is one of the most important features of MINX because it enables study of the 3D context of a scene and allows the user to detect scene content that would otherwise be difficult to discern in a single, nadir-view image from a conventional satellite instrument such as MODIS. During initial loading of camera images into the animation window, radiance values are converted into top-of-atmosphere bi-directional reflectance factors (BRFs) given by the usual relation:

$$
B R F=\frac{\pi I}{\mu_{0} F_{0}}
$$

where $I$ is the radiance (with units of $\mathrm{W} \cdot \mathrm{sr}^{-1} \cdot \mathrm{m}^{-2}$ ), $\mu_{0}$ is the cosine of the solar zenith angle, and $F_{0}$ is the extraterrestrial solar irradiance convolved with the MISR bandpass for that particular wavelength.

The animation window is the workspace in which a user digitizes the boundary of a polygon inside which heights and winds are retrieved on a grid of regularly spaced points. Figure 1 shows the result of digitizing the outline of a plume (dashed aqua line) and a wind direction (yellow arrow along plume axis) and of computing wind-corrected heights. Red dots represent MODIS thermal anomalies from the MOD14 product, often associated with fire hot spots [47,48], which can be processed using a MINX utility function and then displayed on the MISR image. The animation window shows the MISR nadir camera imagery in its original SOM projection. The motion of the satellite relative to the animation window is from the top to the bottom as the Terra satellite descends on the day lit side of the Earth. For most scenes, such as the one shown in Figure 1, this means that the image is oriented approximately north-south, with north toward the top of the image and west to the left. Selecting the Geography toggle on the animation window, overlays a latitude-longitude grid and geographic outlines, to assist in orienting the user. 
Figure 1. The MISR nadir camera image for orbit 24298, block 37 in the image pane of the MINX animation window after one block of level 1 terrain-referenced radiance data has been loaded, after MODIS thermal anomaly retrievals have been over-posted (red dots) and after wind-corrected heights have been retrieved for one plume (represented by colors inside the plume polygon). The large wildfire plumes on the right half of this image were captured over eastern Alaska on 12 July 2004. Five plumes in this image are associated with fires each producing from 3 to 6 gigawatts of radiative power as measured by MODIS. The dashed, aqua outline of the plume polygon and the yellow wind direction arrow were digitized with a mouse. The color key shows aerosol height above sea level.

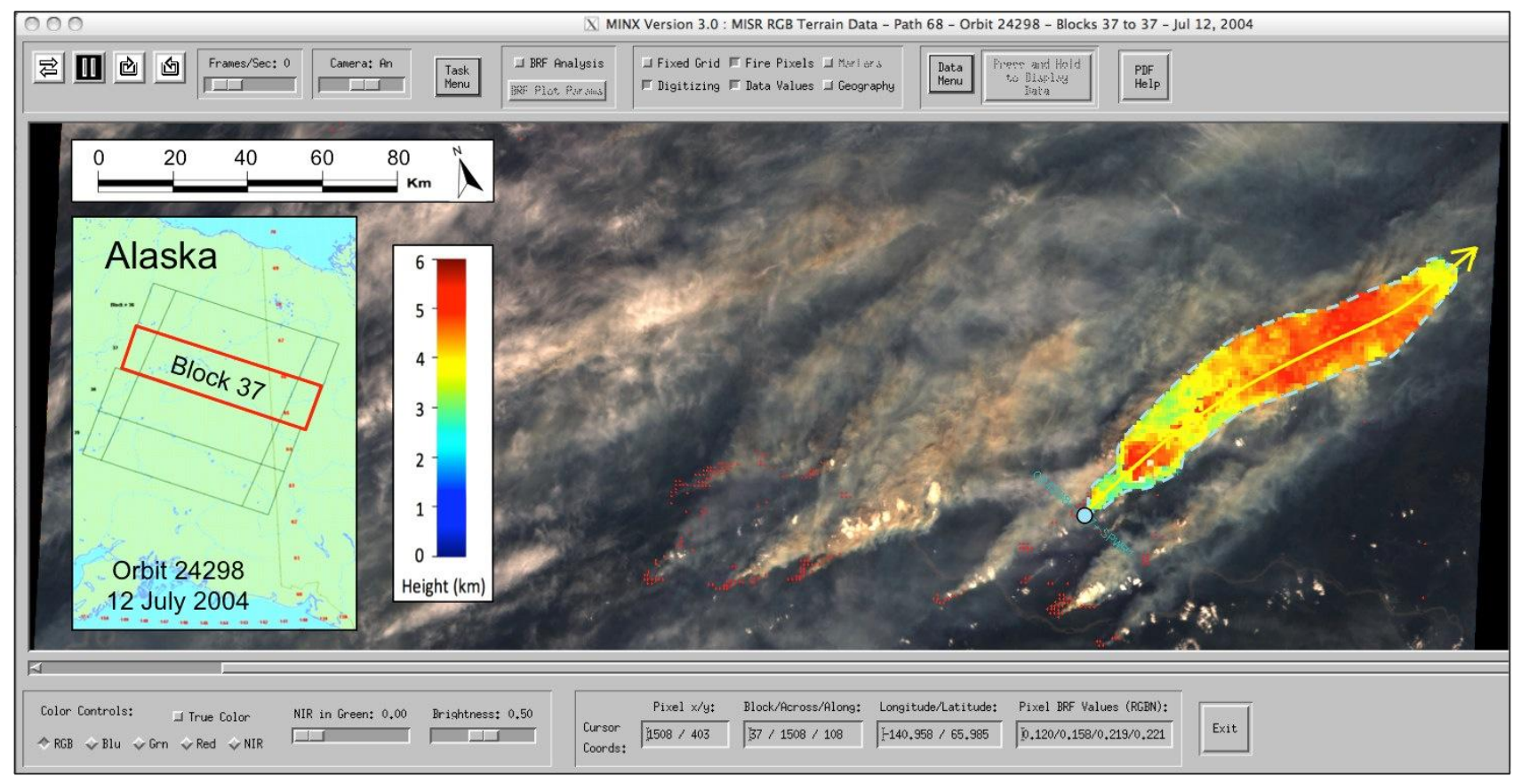

The wind direction was defined using several non-co-linear points to illustrate that MINX interpolates the line with a cubic spline. Wind directions are computed and stored at uniform spacing along this curve. When stereo retrievals are performed on a pixel inside the digitized polygon, the wind direction from the point on the curve nearest that pixel is used. Figure 2a,b shows the corresponding height and wind profiles generated by MINX for the digitized plume in Figure 1. The height profile in Figure 2a shows zero-wind heights (red points), wind-corrected heights (blue points), and terrain heights (green line), all referenced to sea level. The wind profile in Figure $2 \mathrm{~b}$ shows the components of the wind in the across-track (green points) and along-track (magenta points) directions. In this figure, positive across-track motion represents features that move from left to right in the MINX animation window, corresponding to winds that blow from nearly west to east. Positive along-track winds are associated with features moving from the bottom to the top of the MINX animation window, corresponding to winds that blow nearly from south to north. The profiles in Figure 2a,b share a distance axis on which the origin is the first point digitized in the animation window (the aqua circle near the source of the plume at the lower left of the digitized polygon in Figure 1).

In this example, the wind-corrected height of the plume increases from about $3 \mathrm{~km}$ above sea level (ASL) near the initial height retrievals to over $5 \mathrm{~km}$ ASL in a turbulent pulse of rising smoke above the active fire. Then it drops to under $4 \mathrm{~km}$ before rebounding to $5 \mathrm{~km}$ ASL at about $80 \mathrm{~km}$ downwind. 
Retrieved heights above the rising smoke may have reduced accuracy if the plume is not in a buoyant state, because the MINX algorithm assumes only horizontal motion. The wind speeds show more variability near the fire than downwind, where the mean cross-track component of the wind, $v_{c t}$, temporarily stabilizes at about $6 \mathrm{~m} \cdot \mathrm{s}^{-1}$, with an along-track component, $v_{a t}, \mathrm{of} 3 \mathrm{~m} \cdot \mathrm{s}^{-1}$. The vector sum of these speeds $w_{s}=\sqrt{v_{a t}^{2}+v_{c t}^{2}}$ yields a total wind speed, $w_{s}$, of about $7 \mathrm{~m} \cdot \mathrm{s}^{-1}$.

Figure 2. Data profiles produced automatically by MINX for the plume polygon digitized in Figure 1. Both profiles share a distance axis defined relative to the initial point digitized. (a) Height profiles: zero-wind heights in $\mathrm{km}$ are colored red, wind-corrected heights are blue and terrain heights are green. (b) Wind profiles: wind speeds in $\mathrm{m} \cdot \mathrm{s}^{-1}$ across track are colored light green and wind speeds along track are magenta.
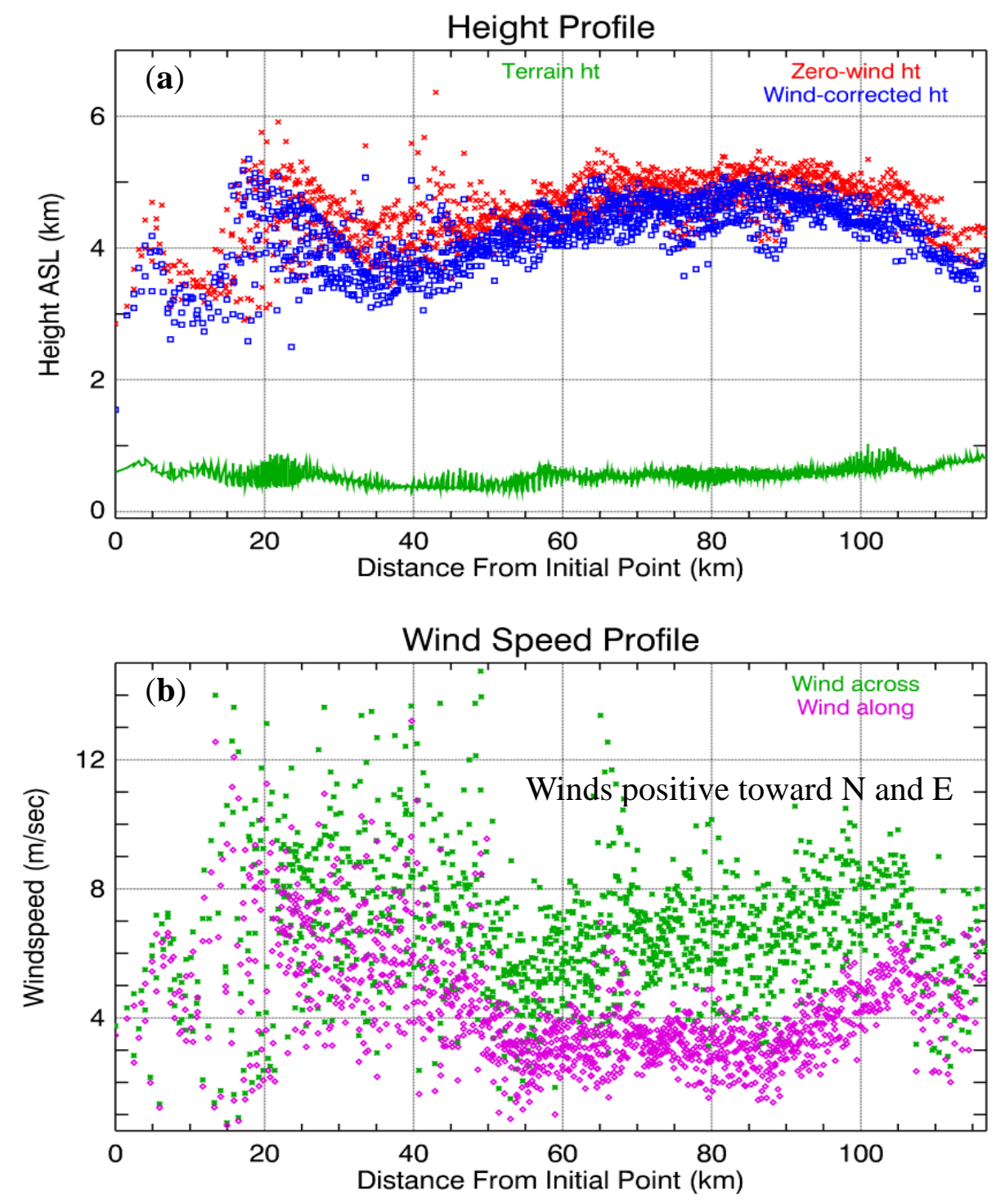

Because all the points in a plume are projected into the plane of the height/wind profiles, there may be multiple plume height, terrain height, and wind speed values at the same linear distance from the initial point. This can produce a spread in data values that can clutter the display, but can represent real variability. To produce a more focused profile, a narrower polygon can be digitized. Alternatively, MINX allows a single line to be digitized instead of a polygon. In this case the line acts as the set of 
points to be sampled and also provides the wind direction at each point. Details on using the MINX software are provided in the MINX on-line documentation [49] and additional information for users can be found in [50].

\section{Camera Registration Correction}

The previous sections were meant to provide the reader with some background and context for understanding the MINX software tool. The following sections provide more detailed information about the algorithms used in the software and their associated assumptions and limitations. This information is provided so that users can make the best use of MINX in their own investigations.

First, it is important that all off-nadir cameras selected for image matching are paired with the An (nadir-viewing) camera during MINX stereo retrievals. If a feature of interest is visible in non-nadir cameras, but not in the An camera, MINX will not be able to perform a stereo retrieval for the feature. Imagery for each camera pair must be geometrically registered to a high degree of precision to minimize errors in the retrieved heights [43]. One pixel $(275 \mathrm{~m})$ of co-registration error (measured relative to the An camera) translates into $560 \mathrm{~m}$ of error in plume height for the Af/Aa $\left( \pm 26^{\circ}\right)$ cameras, $260 \mathrm{~m}$ for the $\mathrm{Bf} / \mathrm{Ba}\left( \pm 46^{\circ}\right)$ cameras, and $160 \mathrm{~m}$ for the $\mathrm{Cf} / \mathrm{Ca}\left( \pm 60^{\circ}\right)$ cameras $[14,15]$. The mean geometric co-registration error of MISR's nine cameras is typically better than 1 pixel as shown in Table 1 [51]. The measurements are in units of $275 \mathrm{~m}$ pixels, and the statistics are based on an analysis of 40 orbits. These statistics are well within the design specifications for the instrument [42]. Nevertheless, it is not unusual to find one or more cameras in a scene that are locally misregistered by at least one pixel, so before digitizing part of any scene over land, the camera images should be visually inspected for co-registration errors by looking for shifts in the apparent position of the terrain surface when viewing the angle-to-angle image animation. A "fixed grid" option, which overlays a grid of crosses on the imagery, is provided within the GUI to assist users with this evaluation.

Table 1. Camera co-registration errors.

\begin{tabular}{ccc}
\hline Camera & Mean & Standard Deviation \\
\hline $\mathrm{Da}$ & -0.04 & 0.26 \\
$\mathrm{Df}$ & -0.03 & 0.25 \\
$\mathrm{Ca}$ & 0.01 & 0.25 \\
$\mathrm{Cf}$ & 0.03 & 0.24 \\
$\mathrm{Ba}$ & 0.01 & 0.16 \\
$\mathrm{Bf}$ & 0.01 & 0.18 \\
$\mathrm{Aa}$ & 0.01 & 0.15 \\
$\mathrm{Af}$ & 0.00 & 0.14 \\
\hline
\end{tabular}

Some misregistration errors are correctable in MINX. Only terrain-referenced imagery containing scenes with a significant fraction of clearly visible land can be successfully evaluated for registration errors. MINX corrects these errors by comparing each camera image to the An image, which is used as the reference. A grid of "control points" is automatically established for which displacements between terrain features are measured. These displacements or disparities are provided to a native IDL procedure that smoothly warps the off-nadir camera image by fractional pixel amounts to more closely match the An reference image. Only displacements less than $N$ pixels are passed into the analysis in order to 
exclude matches on atmospheric features above the terrain to the extent possible. $N$ is camera dependent. For the A and B cameras $N=2$, for the $\mathrm{C}$ cameras $N=3$, and for the D cameras $N=4$. MINX is conservative in applying registration corrections and operates only on misregistration variations with low spatial frequency. Registration problems caused by blunders in the original digital elevation model (DEM) provided in the MISR AGP files [52] cannot be automatically corrected.

\section{Stereo Retrieval}

The MINX retrieval begins with an image-matching step that measures feature disparities for a camera pair. Then the disparities, the camera's viewing geometry, and a spherical Earth model that includes terrain heights are used to compute a linear set of potential solutions. Next, the user-supplied wind direction is intersected with the solution line to give a height/wind-across-track/wind-along-track solution triplet for this camera pair. When these steps are complete for all camera pairs at a sample point, a maximum of eight sets of height and wind values are available, depending on the number of cameras selected for matching and the number of successful retrieval attempts (attempts that produced a height value). The last step is to determine a consensus height and winds. The algorithmic approach used in each of these steps is described in greater detail below.

\subsection{Height, Wind, Parallax, and Disparities}

A feature above the Earth's surface is seen by each of MISR's cameras over a seven-minute period from nine different angles as the Terra satellite passes overhead. Parallax shift causes the feature to project onto the terrain at different locations in each camera [53]. The projected location will shift increasingly toward the top of MISR images as they are viewed successively in MINX in forward chronological order (Df, Cf, Bf, Af, An, Aa, Ba, Ca, Da). The displacement in feature location between two cameras is its disparity and consists of an along-track displacement parallel to the ground track of the satellite and an across-track displacement in the orthogonal direction. The measurement of these two components of disparity provides the raw data for computing stereoscopic heights and winds [16].

In the general case of a feature that is not stationary, there are three unknowns to be determined: height, wind speed in the along-track direction, and wind speed in the across-track direction (Both MINX and the MISR operational stereo products assume no vertical motion [14,15], a reasonable assumption in most natural situations. In the presence of a large component of vertical motion, retrieved heights will be less accurate.) The problem is under-determined (two equations and three unknowns) for a single camera pair, but adding a third, non-symmetric, camera provides a solution $[14,15]$. This is the approach used in the MISR operational stereo products where all three unknowns must be determined automatically.

\subsection{Retrieving Height with No Wind}

In the special case of a feature that is motionless, its across-track and along-track disparities due to motion are zero, and its across-track disparity due to parallax is zero, while its along-track disparity is non-zero and due entirely to parallax. The single unknown, height, can be approximated using the relation:

$$
d=h \cdot \tan \Theta
$$


where $d$ is the along-track disparity between the nadir view and the off-nadir view, $h$ is the height, and $\Theta$ is the viewing zenith angle of the off-nadir camera [53]. In the general case of a feature in motion, a "zero-wind" height can be obtained by assuming the entire along-track disparity is due to parallax. This can be a useful metric, particularly when a full wind-corrected retrieval cannot be performed, but the result can be in error by tens of meters to kilometers, depending on true feature height, camera pair used, and actual wind speed.

\subsection{Retrieving Height with across-Track Wind Only}

If there is a component of wind across-track but the along-track component is zero, then there are two unknowns that do not depend on one another, height and across-track wind speed. The two measurements, across-track disparity due to motion and along-track disparity due to parallax, are also independent. The determination of height in this case is identical to the "No Wind" case - it is uniquely determined by the along-track disparity, since the only contributing factor is parallax. The determination of across-track wind speed is uniquely determined by the across-track disparity. One can approximate across-track wind speed by converting across-track disparity to map distance then dividing by the time between the two cameras' observations. In practice the calculation must consider Earth curvature (which is more important near the edges of the image swath), terrain height, and other factors.

\subsection{Retrieving Height with across-Track and Along-Track Winds}

When both across-track and along-track components of wind are present, the across-track component of motion can still be estimated from the across-track disparity between two cameras using the method described above. However, the along-track disparity includes contributions from parallax due to height and from real displacement due to along-track wind. Consequently a wind-corrected height must be computed that is different from the zero-wind height. There are now two unknowns remaining (height and along-track wind) with only one measurement (along-track disparity) available to untangle them.

An important innovation in the MINX stereo retrieval algorithm is the ability to incorporate a user-defined wind direction, which provides an additional constraint to the problem. This is accomplished by requiring the user to select, or "digitize," two or more points with the mouse that define a straight or curved line representing the plume's motion in response to the mean atmospheric wind. For any point on this line, the wind direction can be represented by the slope of the digitized line, which is the ratio of the along-track and across-track transport distances as well as the ratio of the wind speeds. In other words:

$$
S=\frac{D_{\text {along }}}{D_{\text {across }}}=\frac{v_{a t}}{v_{c t}}
$$

where $S$ is the slope, $D$ is the transport distance either along-track or across-track, and $v$ represents the component of the wind in the along-track $\left(v_{a t}\right)$ or across-track $\left(v_{c t}\right)$ directions, as before. If one wind speed is known, for example $v_{c t}$, the other is easily obtained from the slope of the line and Equation (3). Now the two remaining unknowns (along-track wind and height) can be determined simultaneously using a single camera pair. Additionally, this approach eliminates the need to use MISR's D cameras for wind retrievals, resulting in better signal-to-noise so spatial averaging [16] is not required, allowing the full vector wind to be retrieved at high spatial resolution. 


\subsection{Retrieval Algorithm Overview}

The stereo retrieval algorithm used in MINX is applied independently to each sample point inside a digitized polygon or on a digitized line. At each point, the stereo retrieval is performed independently for each of several camera pairs to take advantage of MISR's multiple-camera redundancy. The An (nadir) camera, which serves as the reference image for all camera pairings, is displayed in the MINX GUI animation window during digitizing. The An camera is used as the reference for two reasons. First, at the center of the swath, the L1B2 processing projects features in the An camera directly downward $\left(\Theta=0^{\circ}\right)$, whereas at the margins of the swath $\Theta \approx 18^{\circ}$, so a $5 \mathrm{~km}$ high feature is projected only $1.6 \mathrm{~km}$ from its actual vertical position. By contrast, $C$ camera zenith angles vary from $\Theta=60^{\circ}$ to $62^{\circ}$, causing the projected location of a $5 \mathrm{~km}$ high feature to deviate from its true location by $9 \mathrm{~km}$. This means that the An projection has the smallest parallax and best represents the actual location of features above the terrain. Second, MINX attempts to perform stereo retrievals using as many camera pairs as possible. Because the An camera is centrally located, it provides the best choice for use with both forward-looking and aft-looking cameras. The disadvantages of using the An camera are that atmospheric path length is smaller than for the other MISR cameras so that optically thin aerosols are less easily discriminated from the background, and the swath width of the An camera is slightly narrower than the other cameras, so features at the edge of the MISR swath might not be captured in the nadir view.

MINX allows the user to choose which cameras to pair with the nadir camera for image comparison. In practice, the choice depends largely on considerations of plume topology and processing time. Features on topologically complex or rapidly changing cumuliform surfaces become increasingly distorted due to perspective change and temporal evolution as the viewing zenith angle of the comparison camera increases from A to D. Differences in shadows also become accentuated. This challenges the image matcher, described below, and increases the likelihood of spurious matches. Using only A and B cameras is indicated when plume topology is very complex and rapidly changing, as in the eye-wall of a hurricane to give an extreme example. Adding the D cameras generally improves retrieval results only in cases where the plume surface, such as a boundary layer cloud field, is relatively flat. Including cameras with large view angles also results in greater than linear increases in processing time, because more oblique angles produce larger parallax shifts and require larger comparison images in which to perform image matching as discussed in the next section.

\subsection{Image Matching}

MINX uses a template-based image matcher whose cost metric is the Pearson correlation coefficient given by:

$$
r_{x y}=\frac{\sum_{i=1}^{n}\left(x_{i}-\bar{x}\right)\left(y_{i}-\bar{y}\right)}{(n-1) s_{x} s_{y}}
$$

where $x_{i}$ and $y_{i}$ are top-of-atmosphere BRF values for the $i^{\text {th }}$ pixel in image patches extracted from a camera pair, $\bar{x}$ and $\bar{y}$ are the sample means of the BRFs, and $s_{x}$ and $s_{y}$ are the sample standard deviations. The template is a square patch of $275 \mathrm{~m}$ (or 1,100 m) red-band pixels centered on the pixel to be analyzed in the reference (An camera) image. The template is successively overlain on the comparison image and centered over all possible pixels where a match could occur. At each pixel position, the 
correlation coefficient between the reference patch and the corresponding comparison patch is computed and stored in a correlation matrix.

The image-matcher is applied to red-band data in two passes of a pyramid scheme to reduce computation time. In the first pass, a template from the reference image and a target from the comparison image are resampled to $1.1 \mathrm{~km}$ in each dimension using simple pixel averaging. In the second pass, the full $275 \mathrm{~m}$ resolution of the red band is used. Once a target pixel in the comparison image is found whose patch best corresponds with the reference template, the match is refined to sub-pixel resolution by fitting a cubic-polynomial surface to the correlation matrix, interpolating the coefficients to a 0.2 pixel grid and locating the sub-pixel grid coordinate with the largest correlation coefficient.

Figure 3. Zero-wind height retrievals over a single $1 \mathrm{~km}$ diameter cloud on orbit 40123, block 104, using different image matcher template sizes to demonstrate their smearing effect. The dashed aqua lines represent the digitized polygon inside which height retrievals are attempted.

(a) Image with small cloud at center; (b) heights using $7 \times 7$ pixel template; (c) heights using $9 \times 9$ template; (d) heights using $13 \times 13$ template; and (e) heights using $23 \times 23$ template.
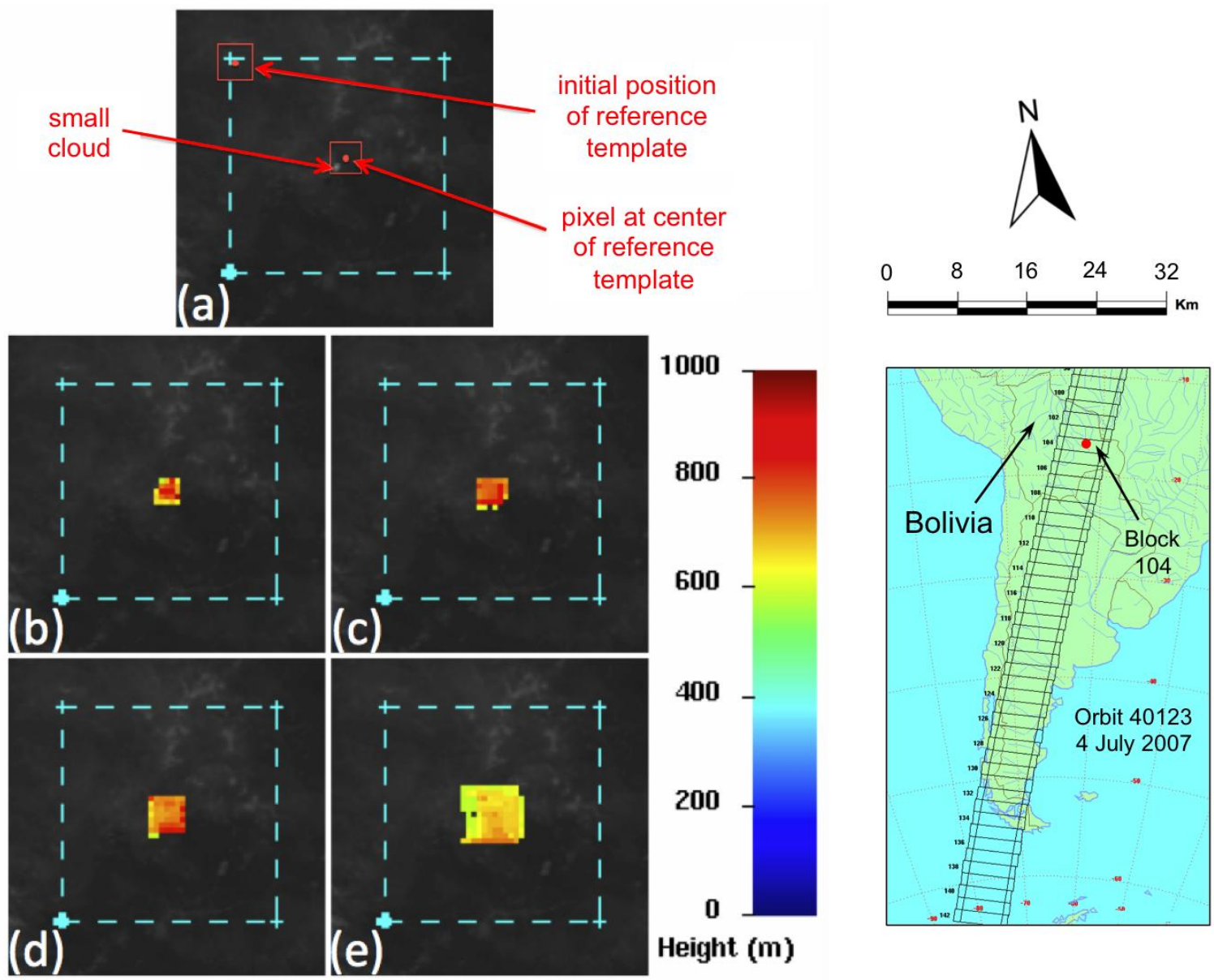

It is more accurate to attribute correlation coefficients and matcher results to entire template-sized areas than to single pixels at the center of the matcher templates. Figures 3 and 4 illustrate this on two different cloud scenes by varying the size of the template used in the retrieval. In Figure $3 \mathrm{a}$, a single cloud less than $1 \mathrm{~km}$ in diameter and $1 \mathrm{~km}$ above the surface is centered in the image. The rest of the scene consists of mottled, dark terrain. The dashed cyan box encloses the comparison region where matching was attempted. Figure $3 b-e$ shows color-coded, zero-wind heights at pixel locations spaced by 
$550 \mathrm{~m}$ (two $275 \mathrm{~m}$ pixels) retrieved with successively larger matcher templates, which are user selectable and listed in Table 2. Although the cloud itself is smaller than any of the templates, the area over which MINX retrieves heights extends outside the bounds of the cloud and is approximately the size of the template. This is best understood by inspecting Figure 3a, in which a red square the size of the Medium image matcher is placed over the cloud. The center pixel of the matcher template, where the result of the correlation operation will be placed, is indicated by the red dot in the center of the template's outline. Although the center pixel does not touch the cloud, pixels on the edge of the template that include the cloud generate a strong response that dominates the correlation.

Figure 4. Zero-wind height retrievals over 2-12 km high clouds on orbit 58978, block 106, using different matcher template sizes to demonstrate their smoothing effect. The dashed aqua lines represent the digitized polygon inside which height retrievals are attempted. (a) Image of cloud field; (b) heights using $7 \times 7$ pixel template; (c) heights using $9 \times 9$ template; (d) heights using $13 \times 13$ template; and (e) heights using $23 \times 23$ template.

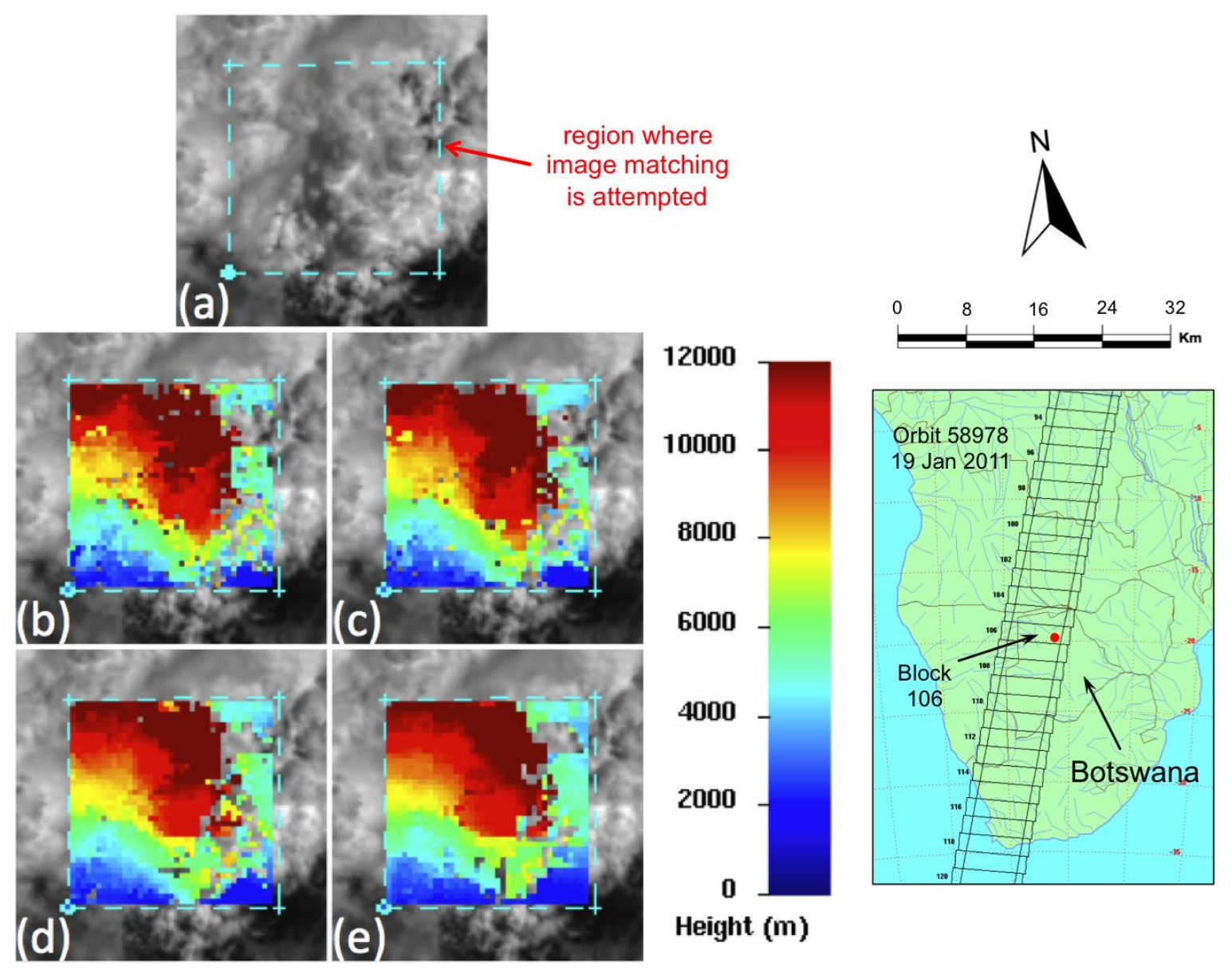

Figure 4a shows an overcast scene with complex cumulus features whose zero-wind heights vary from 2 to $12 \mathrm{~km}$. Figure $4 \mathrm{~b}-\mathrm{e}$ was made in an identical fashion to the panels in Figure 3 . The predominant effect of increasing template size on the cloudy texture in Figure 4 is to spatially smooth the details of the height field, illustrating that the image-matching process operates like a smoothing filter. This is most clearly seen in the comparison of Figure 4b,e.

Image matching is easily the most CPU intensive step in the stereo retrieval process. The CPU time required to compute disparities with different size matchers is highly dependent on hardware. For 
example, on a $3.4 \mathrm{GHz}$ Quad-Core iMac with OS X 10.8 (Mountain Lion) and 16 gigabytes of memory, the elapsed time to complete the image-matching step on a large smoke plume containing over 6,000 points is $88 \mathrm{~s}$ for the Small matcher and $176 \mathrm{~s}$ for the Large matcher. The CPU time is approximately linear with matcher area.

The disadvantages of the larger templates can sometimes be offset by their ability to reduce noise yielding more robust correlations that can significantly improve retrieval coverage. Smaller matchers are most appropriate when fine spatial detail is important and a scene has good data quality or has small-scale variations in plume height. Selecting the appropriate template size for a scene is a matter of user experience and, often, trial-and-error.

Table 2. Matcher template sizes $(\mathrm{N} \times \mathrm{N}$ pixels $)$.

\begin{tabular}{cccc}
\hline Matcher Option & Camera & Pass1 & Pass2 \\
\hline Small & $\mathrm{Af} / \mathrm{Aa}$ & 9 & 7 \\
& $\mathrm{Bf} / \mathrm{Ba}$ & 9 & 7 \\
& $\mathrm{Cf} / \mathrm{Ca}$ & 11 & 9 \\
& $\mathrm{Df} / \mathrm{Da}$ & 11 & 11 \\
Medium & $\mathrm{Af} / \mathrm{Aa}$ & 9 & 9 \\
(default) & $\mathrm{Bf} / \mathrm{Ba}$ & 9 & 11 \\
& $\mathrm{Cf} / \mathrm{Ca}$ & 11 & 11 \\
Large & $\mathrm{Df} / \mathrm{Da}$ & 11 & 13 \\
& $\mathrm{Af} / \mathrm{Aa}$ & 11 & 13 \\
& $\mathrm{Bf} / \mathrm{Ba}$ & 11 & 15 \\
& $\mathrm{Cf} / \mathrm{Ca}$ & 13 & 17 \\
Extra-large & $\mathrm{Df} / \mathrm{Da}$ & 13 & 19 \\
& $\mathrm{Af} / \mathrm{Aa}$ & 11 & 23 \\
& $\mathrm{Bf} / \mathrm{Ba}$ & 11 & 25 \\
& $\mathrm{Cf} / \mathrm{Ca}$ & 13 & 27 \\
& $\mathrm{Df} / \mathrm{Da}$ & 13 & 29 \\
\hline
\end{tabular}

\subsection{Forward Modeling}

Stereo retrievals are performed in MINX using a spherical Earth model with locally superimposed terrain heights. Separate algorithms are used for zero-wind retrievals and wind-corrected retrievals. Zero-wind heights are computed analytically, but wind-corrected heights and wind speeds are computed in a forward modeling step that is applied independently to along-track and across-track components of feature motion. Across-track winds must also be modeled, because the geometry is more complicated than the simplifications in the above discussions suggest.

Figure 5a illustrates the geometry for the general case of a feature whose motion along-track (from $\mathbf{P}_{\mathbf{1}}$ to $\mathbf{P}_{2}$ ) is opposite to the direction of satellite motion. The camera pair includes the An (nadir) reference camera $\left(\mathrm{Cam}_{1}\right)$ and an aft-looking comparison camera $\left(\mathrm{Cam}_{2}\right)$, which produces a positive time difference $\left(\Delta \mathrm{t}=\mathrm{t}_{2}-\mathrm{t}_{1}>0\right)$ between observations. Constants for this case include local Earth radius of curvature $\mathbf{R}_{\mathbf{e}}$; terrain heights $\mathbf{E}_{\mathbf{1}}$ and $\mathbf{E}_{\mathbf{2}}$ at ground locations $\mathbf{T}_{\mathbf{1}}$ and $\mathbf{T}_{\mathbf{2}}$ where each camera projects the feature; and along-track components of zenith angle for each camera, $\mathbf{Z}_{\mathbf{1}}$ and $\mathbf{Z}_{\mathbf{2}}$. Figure $5 \mathrm{~b}$ is a detailed view of the dotted orange box in Figure 5a, generalized for camera "n", which corresponds to the 
comparison camera. Important intermediate variables include angles $\boldsymbol{\mu}_{\mathbf{1}}$ and $\boldsymbol{\mu}_{\mathbf{2}}$ subtended by a vertical through earth's center and with vertices at feature point locations $\mathbf{P}_{\mathbf{1}}$ and $\mathbf{P}_{\mathbf{2}}$, respectively (seen in Figure $5 b$ ), and several angles each with vertices through Earth's center: angles $\boldsymbol{\Phi}_{\mathbf{1}}$ and $\boldsymbol{\Phi}_{\mathbf{2}}$ between feature point locations and verticals through the terrain points; angle $\boldsymbol{\Omega}$ between $\mathbf{P}_{\mathbf{1}}$ and $\mathbf{P}_{\mathbf{2}}$; angle $\boldsymbol{\beta}$, subtended by the along-track disparity vector; and $\mathbf{d}_{\mathbf{w}}$, the distance the feature travels between observation points $\mathbf{P}_{\mathbf{1}}$ and $\mathbf{P}_{\mathbf{2}}$. The single pertinent measurement is the along-track component of disparity, $\mathbf{D}_{\mathbf{m}}$. Feature height above the Earth's surface, $\mathbf{H}$, is the independent variable in the forward modeling scheme, and wind speed, $\mathbf{W}$, is the dependent variable.

Figure 5. Geometry for computing wind-corrected height and wind speed from measured disparities. (a) Geometry including both reference and comparison camera views of a moving cloud. (b) Detailed view of geometry for one camera in orange box of (a). See text for description.
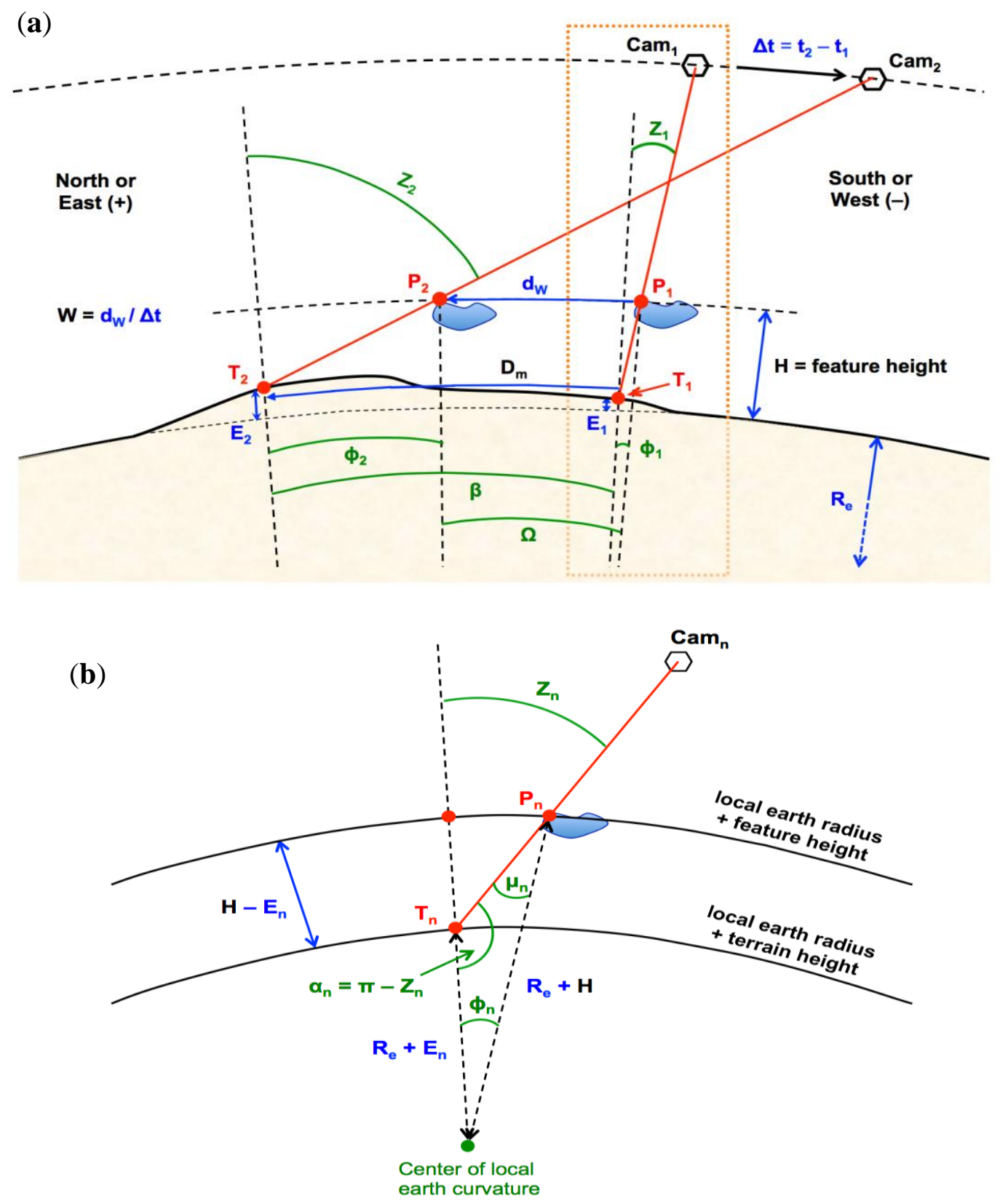
The procedure for determining wind speed $(\mathbf{W})$ given an arbitrary feature height $(\mathbf{H})$ can be summarized as follows:

1. Determine angles $\boldsymbol{\Phi}_{\mathbf{n}}$ from Figure $5 b$

a. From the law of sines: $\left(\mathbf{R}_{\mathbf{e}}+\mathbf{H}\right) / \sin \boldsymbol{\alpha}_{\mathbf{n}}=\left(\mathbf{R}_{\mathbf{e}}+\mathbf{E}\right) / \sin \boldsymbol{\mu}_{\mathbf{n}}$

b. $\boldsymbol{\alpha}_{\mathbf{n}}=\boldsymbol{\pi}-\mathbf{Z}_{\mathbf{n}}$

c. $\boldsymbol{\mu}_{\mathbf{n}}=\sin ^{-1}\left(\sin \boldsymbol{\alpha}_{\mathbf{n}} \times\left(\mathbf{R}_{\mathbf{e}}+\mathbf{E}_{\mathbf{n}}\right) /\left(\mathbf{R}_{\mathbf{e}}+\mathbf{H}\right)\right)$

d. $\Phi_{\mathbf{n}}=\mathbf{Z}_{\mathbf{n}}-\boldsymbol{\mu}_{\mathbf{n}}$

2. Determine $\mathbf{W}$ from Figure $5 \mathrm{a}$

a. $\boldsymbol{\beta}=\mathbf{D}_{\mathrm{m}} /\left(\mathbf{R}_{\mathrm{e}}+\left(\mathbf{E}_{\mathbf{1}}+\mathbf{E}_{\mathbf{2}}\right) / \mathbf{2}\right)$

b. $\boldsymbol{\Omega}=\boldsymbol{\beta}-\boldsymbol{\Phi}_{\mathbf{2}}+\boldsymbol{\Phi}_{1}$

c. $\mathbf{d}_{\mathrm{W}}=\mathbf{\Omega} \times\left(\mathbf{R}_{\mathrm{e}}+\mathbf{H}\right)$

d. $\mathbf{W}=\mathbf{d}_{\mathbf{W}} / \Delta \mathbf{t}$

The relationship between height and wind speed is linear, so the forward modeling procedure must be performed using at least two height values in each of the along-track and across-track directions to define a pair of linear equations: $\mathbf{W}_{\text {across }}=f_{\text {across }}(\mathbf{H})$ and $\mathbf{W}_{\text {along }}=f_{\text {along }}(\mathbf{H})$. In practice, several values of height are used and a regression is performed to ensure that the relationship is indeed linear. The intersection of these equations with the equation for the user's input wind direction, defined by the slope of the direction line ( $S$ in Equation (3)), provides a unique solution to the retrieval problem. The slope of the $\mathbf{W}_{\text {across }}=\mathrm{f}_{\text {across }}(\mathbf{H})$ equation is small, allowing the intercept to stand in as an approximation for the wind speed.

The two linear equations can be represented in 3D-space as a single "solution line". Figure 6 shows a data cube that represents the results from retrieving winds and wind-corrected height at a single sample point for a single camera pair. A triplet of height, wind speed across-track, and wind speed along-track coordinates identifies each point in the cube. The data value at each $3 \mathrm{D}$ coordinate is the difference between the fixed disparities measured by the image matcher and the disparities appropriate to each height/wind-across/wind-along coordinate. The red "Height-wind solution line" represents the set of modeled heights and winds whose disparities exactly match the measured disparities; that is, for every point on the line, the disparity difference is zero. This ambiguity is resolved, as indicated above, by insertion of the green plane representing the user-specified wind direction (yellow arrow). The "Height-wind solution point" marks the intersection of the solution line with the wind direction plane and is the unique solution to the height, wind retrieval problem in MINX.

The data cube is useful for explaining several characteristics of height and wind interactions. For example, the zero-wind height can be found by intersecting the solution line with a plane through the zero-wind axis and parallel to the height, wind-speed-across (XZ) plane. In other words, at an along-track wind speed of zero, the height intersected on the solution line is the zero-wind height. The solution line slopes down in the positive, along-track wind direction $(+Y)$, that is, toward the "top" or north of a MISR swath, opposite to the direction of satellite motion. Therefore, as wind speed toward the north increases, the height must decrease below that of the zero-wind height. Conversely, as wind speed toward the south increases, the height must increase above that of the zero-wind height. It is important to note that zero-wind heights are fictitious and can have values that place them below the terrain surface. 
When this occurs, the user-supplied wind direction must have a component pointing toward the bottom of the image, in which case the wind-corrected heights will be greater than the zero-wind heights and will be corrected to a position above the surface (see Bodele dust case below).

Figure 6. Data cube illustrating MINX forward-modeling results for stereo retrieval at one sample point and for one camera pair. Each point in the cube contains the difference between the measured disparity and the disparity that would be computed for that point's height, across-track wind speed and along-track wind speed. The red line represents the infinite set of solutions for this camera pair; the green plane is constructed from the wind direction (yellow arrow) provided by the user; and the green oval at the intersection of the green wind-direction plane with the red solution line contains the height/wind-speed-across/wind-speed-along solution. Note that the solution line lies in a plane parallel to the along-track wind direction (YZ plane). The zero-wind height can be found at the intersection of the red solution line with a plane containing the zero wind axis and parallel to the across-track wind direction (XZ plane).

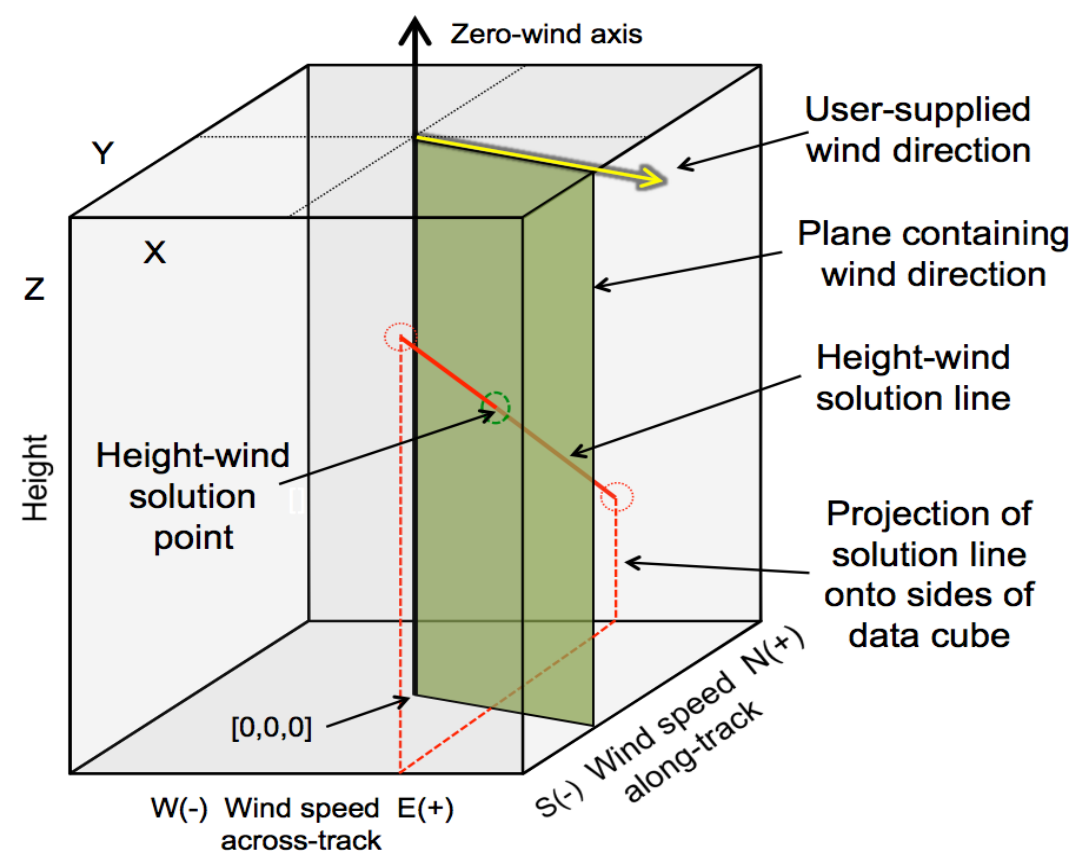

The solution line lies in a plane parallel to the height/wind-speed-along (YZ) plane and can possess values in only one-half the data cube. Consider a feature with a real component of motion toward the right (positive, across-track) side of a MISR image as represented by the data cube in Figure 6. Any user-specified wind direction with a positive, across-track component $(+\mathrm{X})$ will intersect the height-wind solution line and produce a solution. Conversely, an aerosol feature moving in a negative, across-track direction (solution line in the left half-cube) should produce no solution for the user-specified wind direction shown. This provides a useful test during digitizing of ambiguous scenes for determining whether a positive or negative across-track wind direction is more likely correct.

\subsection{Determining Consensus Height and Wind}

When all camera pairs have been processed for a sample point, the retrieved results for the cameras that produced successful matches are inspected to determine a consensus height and wind. This process finds the mean height and wind speed values of those camera pairs whose results cluster most strongly 
around median values. Median values are used to mitigate the degrading effects of outliers. Two clustering passes are executed, and in each pass height-wind results are discarded if they fail to fall within a threshold distance of the median values. Threshold distances are dynamically computed from linear equations whose independent variables are the median height and wind speed being tested. In the first clustering pass, the slope of the height equation is set to 0.45 , and its intercept is $0.75 \mathrm{~km}$. In the second pass, the slope and intercept are 0.3 and $0.5 \mathrm{~km}$ respectively. For the winds, the slope and intercept are 1.5 and $15.0 \mathrm{~m} \cdot \mathrm{s}^{-1}$ in the first pass, and in the second pass they are 1.0 and $10.0 \mathrm{~m} \cdot \mathrm{s}^{-1}$. Wind speeds are more sensitive to variations than heights, so their thresholds are kept loose.

\subsection{Spectral Band}

High spatial resolution data are essential for obtaining high vertical resolution stereo heights. MISR was designed to routinely measure radiances at high resolution $(275 \mathrm{~m})$ in only 12 of 36 channels because of limited instrument data bandwidth [12]. This default setting is called "global mode". MISR can also retrieve high-resolution data in all 36 channels for a limited time, amounting to about $300 \mathrm{~km}$ along-track, on each orbit. This setting is "local mode". The red band was chosen as the high-resolution band in global mode to maximize the contrast between atmospheric aerosols and the Earth's surface over both water and land [12].

Figure 7. Local mode (275 m resolution in all channels) RGB images of a smoke plume on orbit 57201, block 111, for cameras (a) An; (b) Aa; (c) Ba; and (d) Ca.

An

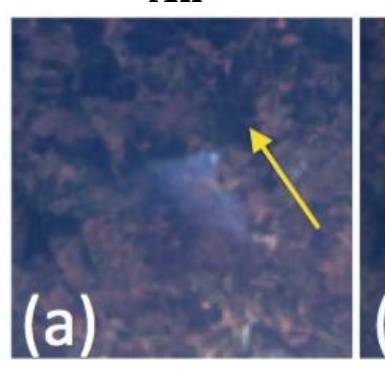

Aa

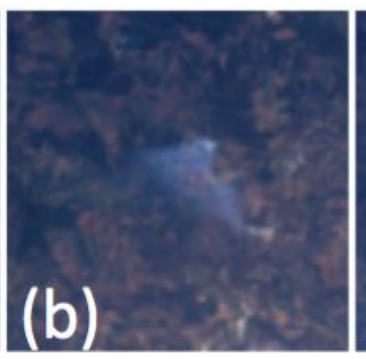

Ba

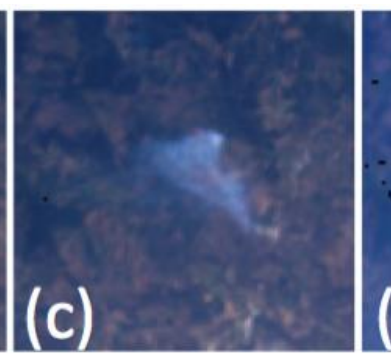

Ca

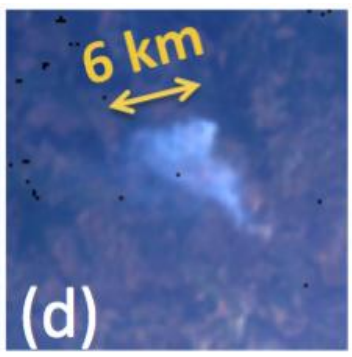

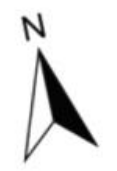
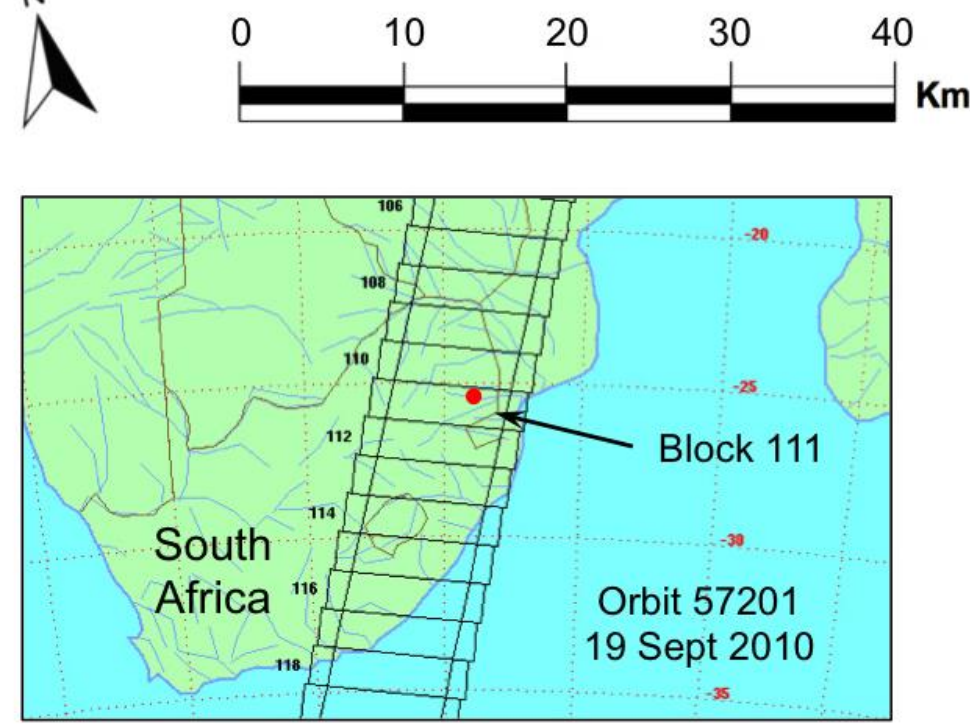
Grasslands, deserts and other scenes can be relatively bright in the red band. When terrain features in these scenes are visible through an aerosol layer, the red band is often not the best choice for retrieving stereo heights [23]. The "true-color" RGB images in Figure 7a-d show a small smoke plume over grasslands near Skukuza, South Africa. These four panels are high-resolution (local mode) images from the An, Aa, Ba and Ca cameras respectively. The yellow arrow in Figure 7a represents the wind direction applied for the wind-corrected height retrieval. The opacity of the smoke increases with camera zenith angle as the optical path length through the smoke increases. The An reference camera, which requires a strong aerosol signal for image matching, sees terrain features through the smoke, making matching difficult. Note that the position of the plume also moves toward the top of the image relative to the ground because of greater parallax in the more oblique cameras.

Figure 8. Single-band, local mode images and height retrieval maps for the scene in Figure 6. Aa camera local mode images for bands: (a) blue; (b) green; (c) red; and (d) NIR. Zero-wind heights for local mode data retrieved using bands: (e) blue; (f) green; (g) red; and

(h) NIR. Wind-corrected heights corresponding to heights in (e-h): (i) blue; (j) green;

(k) red; and (l) NIR.
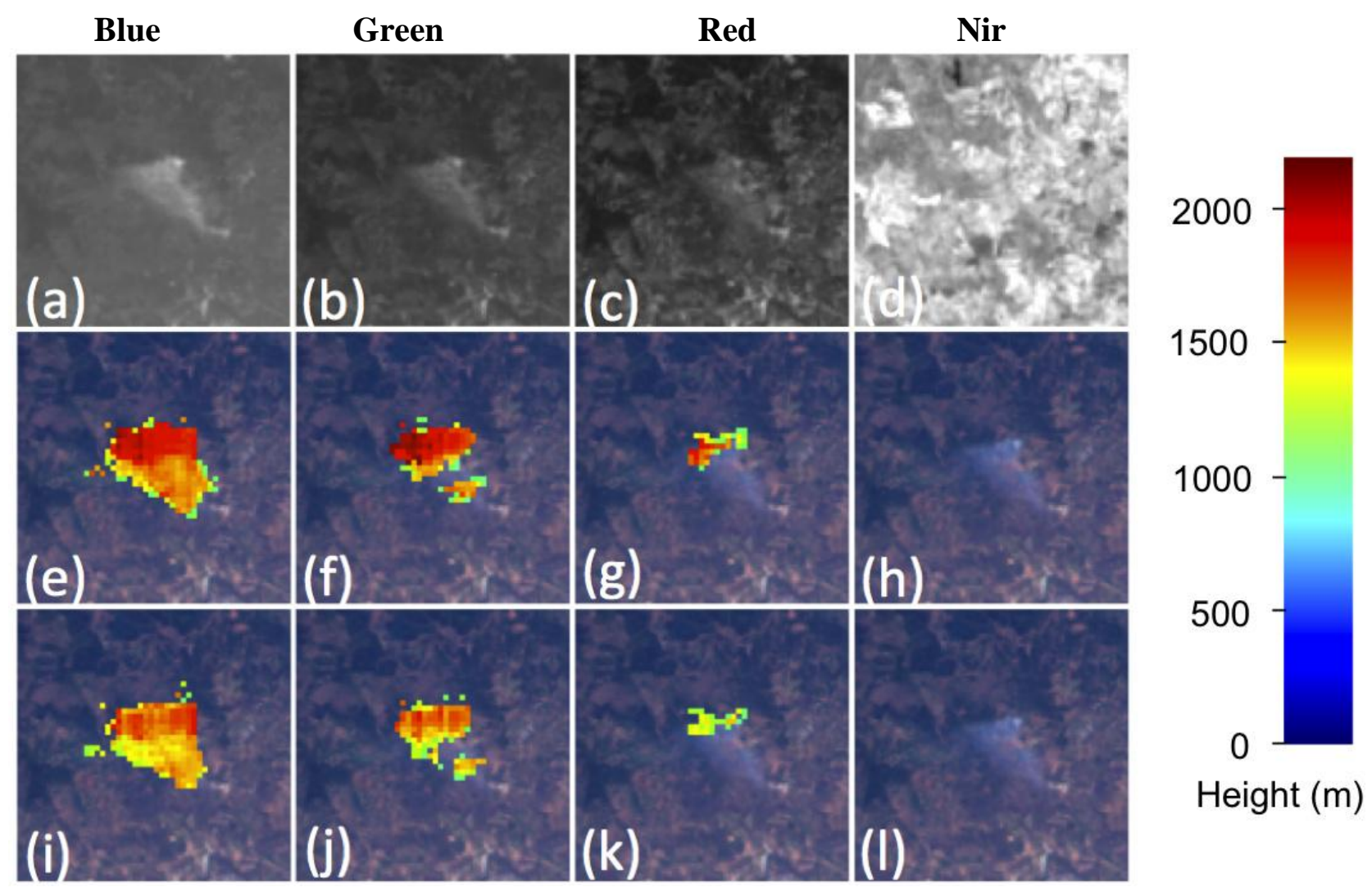

Figure 8a-d shows the same local mode scene from the Aa camera in gray-scale for blue, green, red and NIR bands respectively. As wavelength increases, atmospheric scattering decreases, and the terrain becomes more visible through the smoke. Zero-wind height retrieval results for each local-mode band are shown in Figure 8e- $\mathrm{h}$, and wind-corrected heights are shown in Figure 8i-1. Also note that wind-corrected heights are lower than corresponding zero-wind heights, reflecting the fact that the wind direction has a component directed toward the top of the image in this case. These figures show that stereo retrieval coverage deteriorates dramatically as wavelength increases. Just as significantly, 
blue-band, wind-corrected heights are a few hundred meters greater than corresponding red-band heights. In certain cases, the greater sensitivity of the blue band to thinner aerosols allows aerosol features to be matched that correspond to a higher altitude for the plume. For scenes like this one, the blue band is a better choice for image matching, so MINX allows the user to select a blue-band retrieval algorithm when performing stereo retrievals.

Because local mode data are not available for most MISR scenes, which are acquired in global mode, MINX routinely produces $275 \mathrm{~m}$ "pseudo-high-resolution" images in all channels displayed in the animation window. This sharpening is accomplished by subdividing each 1,100 m pixel into 16-275 m pixels and assigning them BRFs in the same ratio as in the equivalent $275 \mathrm{~m}$ red band pixels for the same camera. The mean BRF of the 16 sharpened pixels is maintained at the level of the original 1,100 m pixel. The panels in Figure 9 are identical to those in Figure 8, except that they use sharpened global mode data rather than local mode data. The gray scale BRF images of the blue, green and NIR bands possess a blocky texture caused by the sharpening algorithm, although the smoke is affected less than the terrain. Heights retrieved using blue and green bands still show significant improvement over red band heights, although they are inferior to equivalent local mode retrievals. Heights retrieved using the NIR band (Figure 9h) are mostly blunders derived from matches on the blocky, sharpened terrain.

Figure 9. Single-band, global mode images and height retrieval maps for the scene in Figure 6. Aa camera global mode images for bands: (a) blue; (b) green; (c) red; and (d) NIR. Zero-wind heights for global mode data retrieved using bands: (e) blue; (f) green; (g) red; and (h) NIR. Wind-corrected heights corresponding to heights in (e-h): (i) blue; (j) green; (k) red; and (l) NIR.
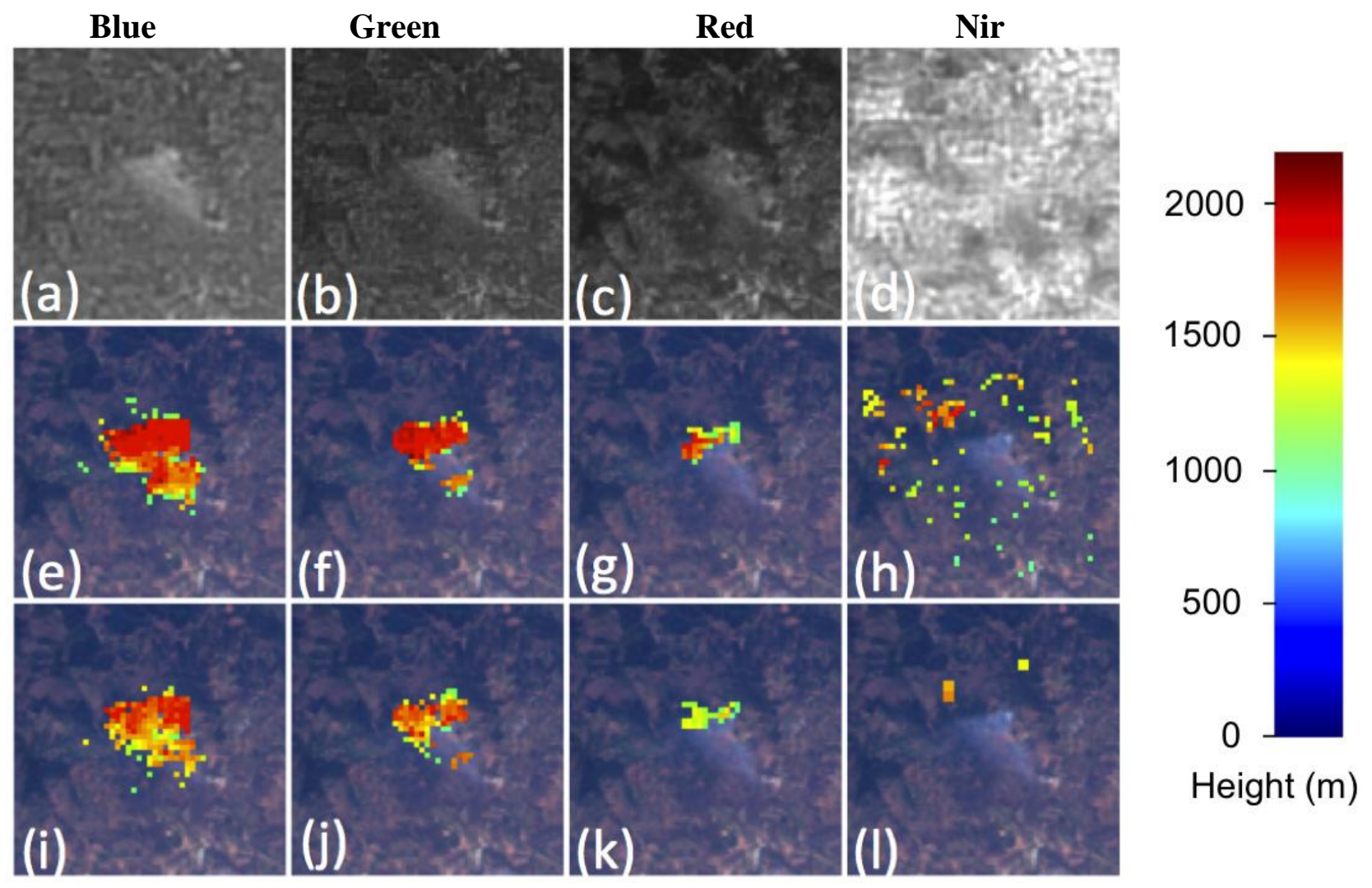


\section{Wind Direction Revisited}

\subsection{Interpreting Wind Direction}

Wind direction is arguably the most important user input to MINX. An incorrect wind direction assigned to a fast-moving aerosol feature can result in wind-corrected height errors of several kilometers. Whereas apparent across-track motion is generally a reliable indicator of true across-track motion, in most cases it is impossible to determine whether the apparent motion of an aerosol feature includes a true component of motion in the along-track direction. In the case of plumes, direction-of-motion can usually be inferred from scene context. But for water or other aerosol "clouds", without an obvious connection to the ground, few clues may be present. Exceptions can sometimes be found when carefully inspecting the MINX animation sequence in forward chronological order. For example, if a feature appears to move from the top toward the bottom of the image, then real motion toward the bottom due to wind is present and exceeds apparent motion toward the top due to parallax. This typically occurs only in cases with high wind speeds and low feature height (see Bodele dust case below). Other useful sources of information for determining wind direction are shadows cast by aerosol features onto the terrain. The motion of a shadow relative to the ground indicates the direction of true motion, both across-track and along-track.

\subsection{Sensitivity of Height to Wind Direction}

Figure 10a-c shows three, large, excellent quality smoke plumes in Alaska during a two-week period in early July 2004. White arrows indicate the true wind direction representative of each, as determined from scene context. Red patches are regions where the plume tops are relatively flat. These patches were digitized multiple times with different assumed wind directions at multiples of $10^{\circ}$ indicated by the yellow arrows. Each patch yielded more than 200 successful and similar-valued zero-wind heights (shown in red) and a variable number of wind-corrected heights (success in this context simply means that the MINX algorithm returned a height value). The results of this analysis are summarized in Figure 11.

The fraction of zero-wind retrievals that produced successful wind-corrected heights (Figure 11a) and the median (Figure 11b) and standard deviation (Figure 11c) of wind-corrected heights were computed and are shown color-coded for each of the plumes in Figure 10. The true wind directions are indicated with vertical arrows. The $\mathrm{x}$-axis of each graph represents assumed wind direction measured in degrees, with zero corresponding to the positive along-track direction (toward the top of the MISR swath) and $+90^{\circ}$ and $-90^{\circ}$ corresponding to across-track directions. Zero-wind heights correspond to retrievals that assume all motion is in the across-track direction $\left( \pm 90^{\circ}\right.$ in Figure $\left.11 \mathrm{~b}\right)$. Because the MINX algorithm cannot retrieve heights corresponding to directly along-track wind, the values on all panels near $0^{\circ}$ and $180^{\circ}$ in Figure 11 are equal to zero. A glance at the data cube in Figure 6 reveals why the MINX algorithm fails when attempting retrievals in the purely along-track direction. When the across-track component of the wind is zero, the solution line lies in the height/along-track wind (YZ) plane through the Zero-wind axis, and cannot uniquely intersect any user-provided wind direction. However, data quality begins to deteriorate before across-track motion reaches exactly zero, because the plane containing the wind direction intersects the solution line at a small angle, leading to increased sensitivity of height and wind speed to noise and small errors in the assigned wind direction. 
Figure 10. Large, flat-topped plumes used in tests of sensitivity of wind-corrected heights to digitized wind direction: (a) Smoke plume trending toward top right on orbit 24298, block 37; (b) smoke plume with only across-track component of motion on orbit 24152, block 40; (c) smoke plume trending toward bottom left on orbit 24123, block 39.
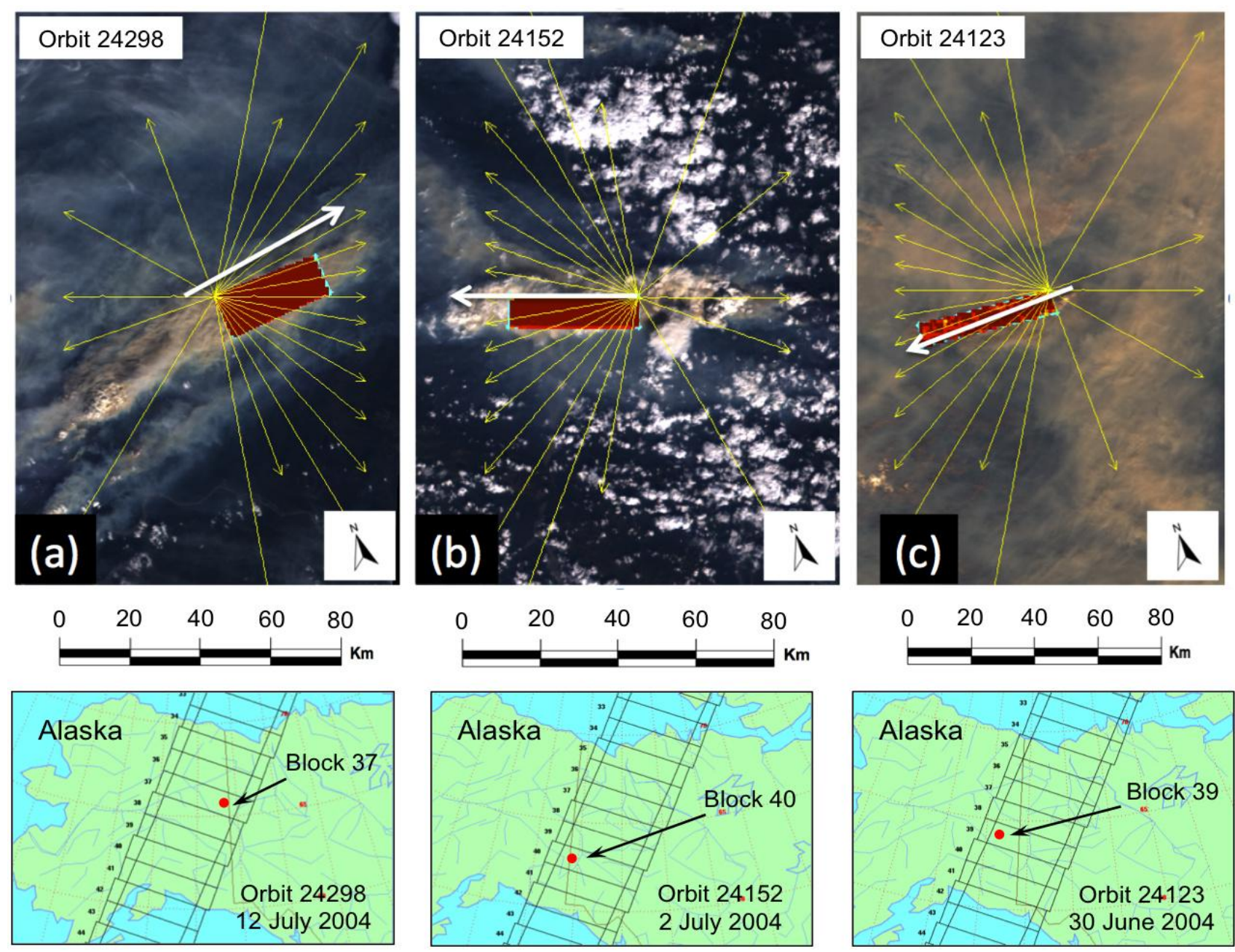

As shown in Figure 11a, successful retrievals of wind-corrected heights are present when the assumed wind direction is either left or right of the along-track direction. In other words, retrievals are possible only when the assumed wind direction is in the same half-plane occupied by the true wind direction. The fraction of successful retrievals varies from case to case, but is generally high within $60^{\circ}$ of the across-track directions $\left( \pm 90^{\circ}\right.$ on the $\mathrm{x}$-axis). Interestingly, coverage remains nearly $100 \%$ for the purely across-track plume corresponding to Figure $10 \mathrm{~b}$, shown in blue, over a range of $120^{\circ}$.

The relationship between wind direction and wind-corrected heights is shown in Figure 11b. For all three plumes, regardless of true wind direction, retrieved wind-corrected heights monotonically decline as the digitized wind direction approaches the positive along-track direction. Consider the simplified situation where the across-track disparity gives a fixed value for the across-track wind speed, $v_{c t}$. Equation (3) provides a method to calculate $v_{a t}$ directly by simply multiplying by the user-defined slope. The slope is related to the assumed wind direction plotted in Figure 11. If the assumed wind direction is $0^{\circ}$, all the wind is in the purely along-track direction. If the assumed wind direction is $90^{\circ}$, all the wind is in the purely across-track direction. At $45^{\circ}$ the wind is divided equally between the along-track and 
across-track direction. Therefore, as the assumed wind direction tends toward $0^{\circ}$, the fraction of the wind in the (positive) along-track direction increases, leading to a decrease in the wind-corrected heights, for the reasons described earlier.

Finally, Figure 11c demonstrates that the standard deviation of retrieved heights tends to be a minimum near the true wind direction. This is because selection of the correct wind direction yields the best match among the retrieved disparities leading to results that are spatially consistent.

Figure 11. Graphs showing relationships of wind-corrected height retrievals to digitized wind direction for the three plumes in Figure 9: (a) The fraction of successful zero-wind retrievals that resulted in successful wind-corrected retrievals; (b) wind-corrected height; (c) standard deviation of wind-corrected heights. Colors represent different plumes in Figure 9. Vertical arrows indicate the "true" wind direction for each plume. Zero-wind directions are -90 and +90 degrees.
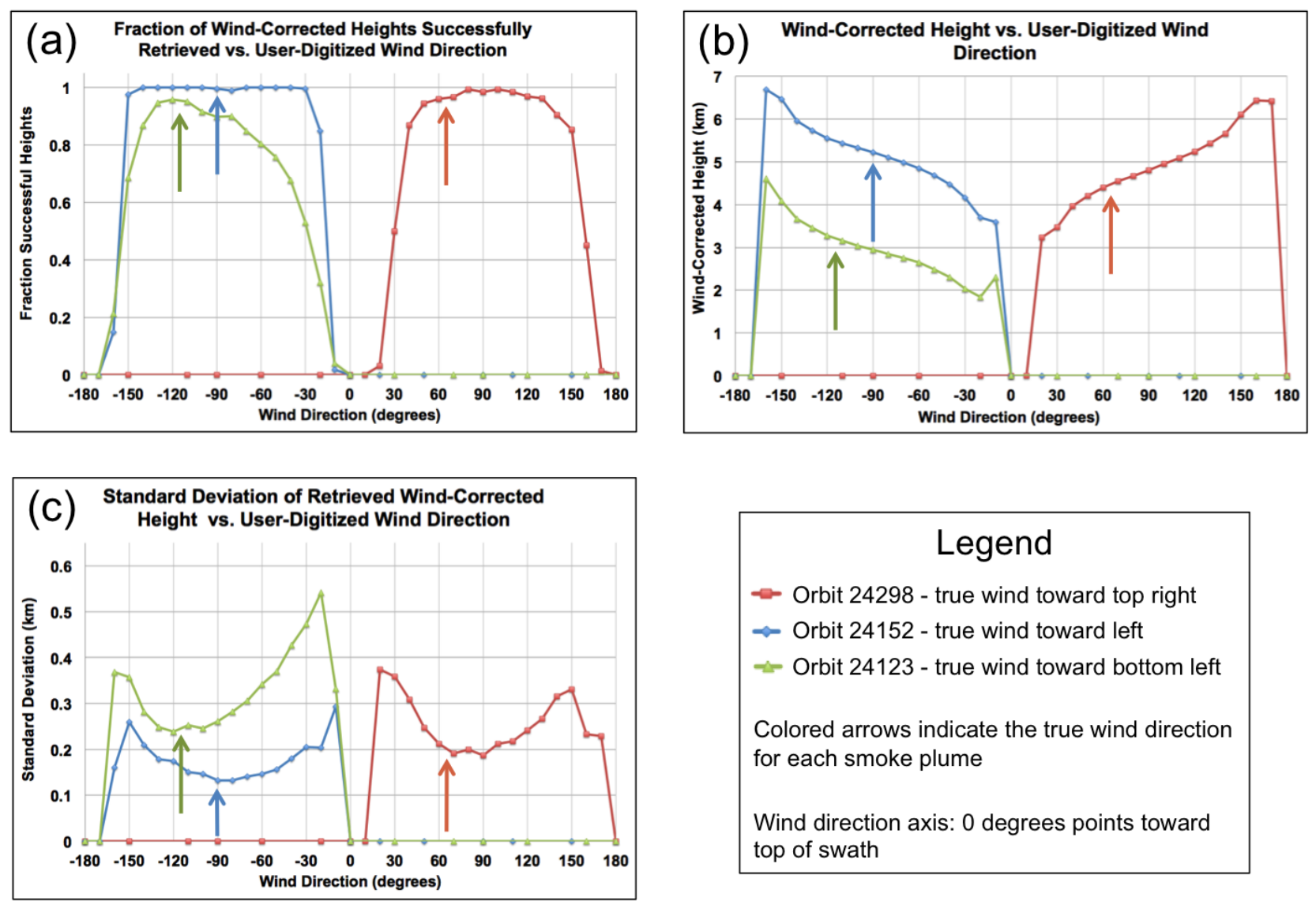

\section{Legend}

- Orbit 24298 - true wind toward top right

$\approx$ Orbit 24152 - true wind toward left

- Orbit 24123 - true wind toward bottom left

Colored arrows indicate the true wind direction for each smoke plume

Wind direction axis: 0 degrees points toward top of swath

\subsection{Negative Heights}

Figure 12a shows a large dust storm in the Bodélé Depression in northern Chad, for which MINX retrieves wind speeds in excess of $20 \mathrm{~m} \cdot \mathrm{s}^{-1}$ (Figure 12c), with an along-track component of wind directed toward the bottom of the image. This region has been identified as one of the largest dust sources on the planet due to the interaction of the nearby terrain and downward momentum mixing from a nocturnal low-level jet that lifts diatomite deposited from paleolake Mega-Chad [54]. The red, zero-wind heights in the profile of Figure $12 \mathrm{~b}$ lie $1 \mathrm{~km}$ below the blue, wind-corrected points and even below both the terrain level (the green line at $0.3 \mathrm{~km}$ elevation) and sea level. Although this is a 
mathematically valid result, it is not physical. Correcting the heights using the appropriate wind speed (blue points) produces reasonable heights at about 0.5 to $1.0 \mathrm{~km}$ above the terrain. Figure $12 \mathrm{~b}$ shows that the dust plume heights increase from near the surface to about $700 \mathrm{~m}$ a distance $100 \mathrm{~km}$ downwind from the source and rise slowly but steadily thereafter. Although other researchers have reported a technique for deriving wind speeds from the Bodélé using the two MODIS instruments on the Terra and Aqua satellites separated in time by nearly three hours [55], MINX using MISR provides a nearly instantaneous retrieval of both heights and winds at high spatial resolution.

Figure 12. Stereo retrieval results along a digitized line for a large dust plume moving toward the lower left (SW) in the Bodele Depression, Chad on orbit 43484, block 77: (a) Nadir RGB image of a portion of plume with color-coded, wind-corrected heights along digitized wind-direction line; (b) profile of zero-wind and wind-corrected heights showing zero-wind heights below terrain level and wind-corrected heights at realistic heights; (c) profile of across-track and along-track wind speeds.
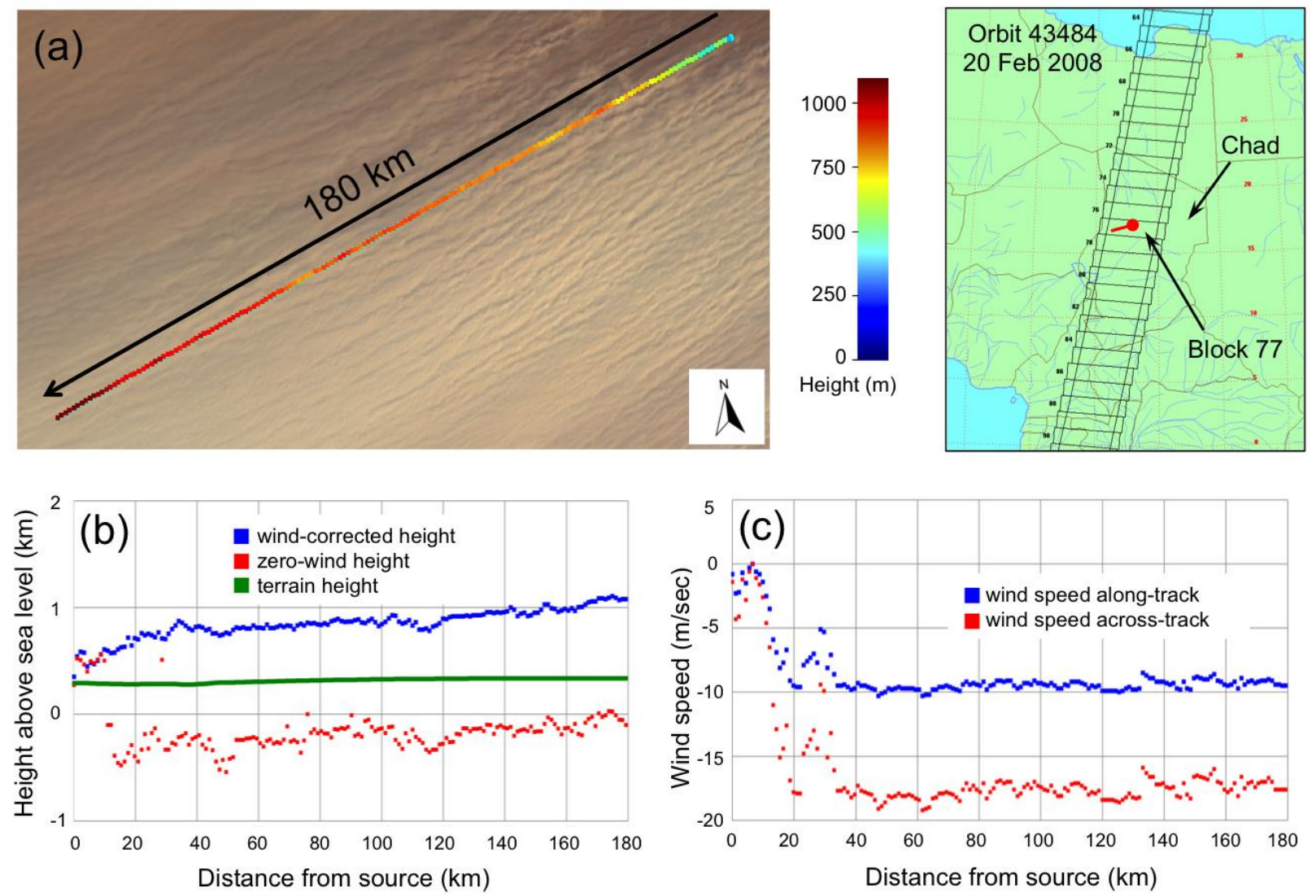

\subsection{Small-Scale Wind Variations}

Figure 13a shows the An (nadir) camera image of an ash plume above the Augustine Volcano in Alaska, captured by MISR on 30 January 2006. The volcano itself is visible in the lower left of the image, with the plume extending to the upper right. The clear pattern of ribs diverging bilaterally from the central spine of the plume is suggestive of plume bifurcation, a phenomenon in which wind shear creates rotating vortices that can separate to produce distinct lobes. Bifurcation similar to the type suggested for Augustine has been observed in other volcanic eruptions and has been modeled and discussed in the literature [56]. 
MINX was used to determine the height of the Augustine plume using a single wind direction. The map of wind-corrected heights and the digitized wind direction are shown in Figure 13b along with the corresponding height profile in Figure 13d. The unusual dichotomy in the heights - approximately $5,500 \mathrm{~m}$ on the northwest side and 4,600 $\mathrm{m}$ on the southeast - suggests that variation in wind direction may be involved. On the assumption that the ribbing represents the direction of ash transport within vortices, the two lobes of the plume were digitized independently using wind directions parallel to the ribbing. Figure 13c,e shows the resulting wind-corrected height map and profile respectively. On the northwest side, wind-corrected heights have dropped by $\sim 200 \mathrm{~m}$; on the southeast side, they have increased by $300-400 \mathrm{~m}$. The range in heights has also been reduced substantially, which suggests that the plume is relatively flat. The height changes are consistent with the observation noted above that wind-corrected heights increase as wind direction is increasingly oriented toward the bottom of the image, and heights decrease as wind direction tends toward the top.

Figure 13. Bifurcated ash plume over Augustine volcano, Alaska, on orbit 32555, block 43: (a) Nadir image of plume showing central spine and diverging ribs indicative of vortices caused by wind shear; (b) wind-corrected heights in map view retrieved using a single wind direction shown by yellow arrow; (c) wind corrected heights in map view retrieved using different wind directions parallel to ribbing in each half of plume; (d) profile of wind-corrected heights retrieved using single wind direction; (e) profile of wind-corrected heights retrieved using two wind directions. Wind-corrected heights in northwest lobe of plume are shown in blue; wind-corrected heights in SE lobe are in red.
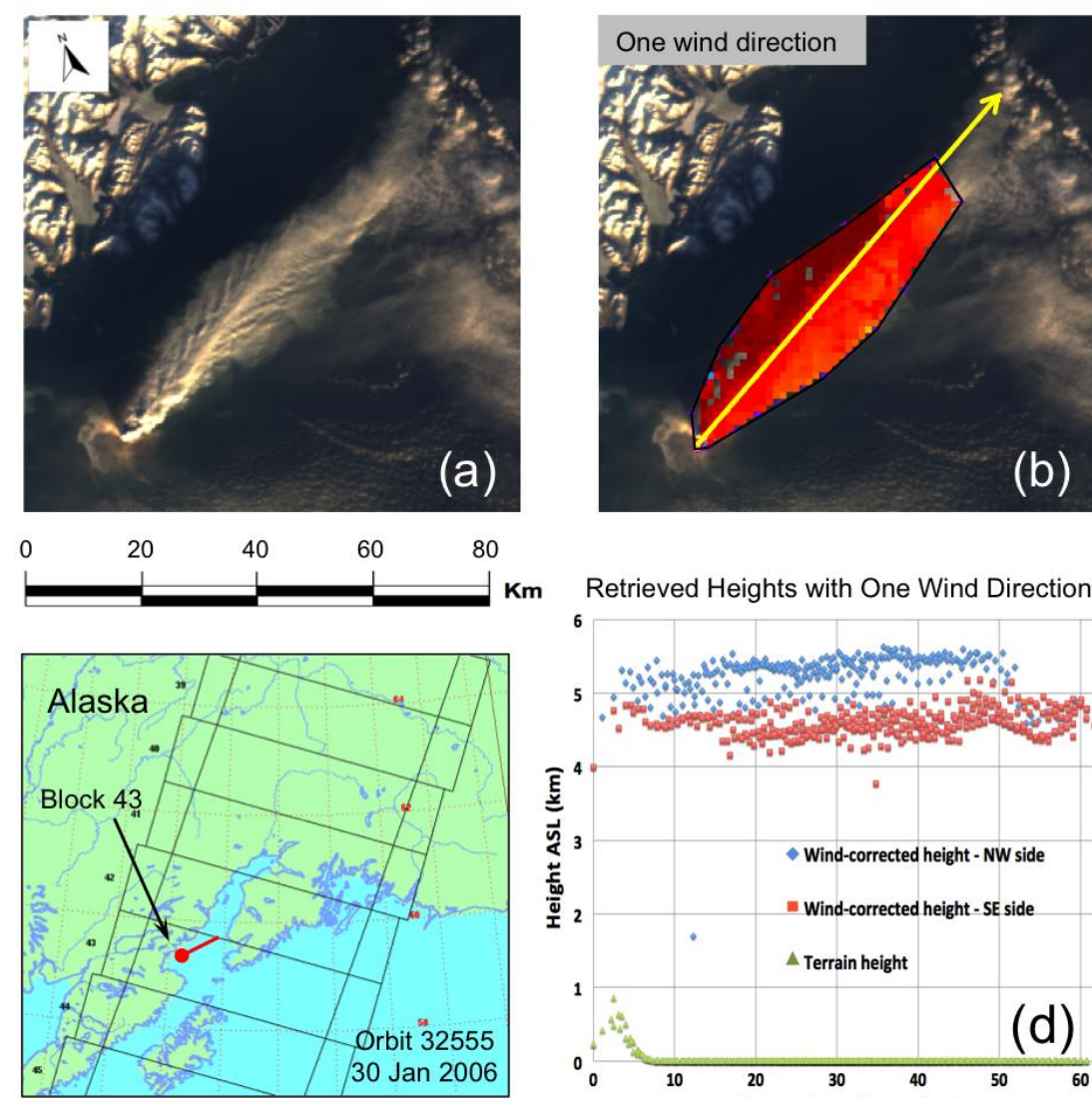

Retrieved Heights with One Wind Direction
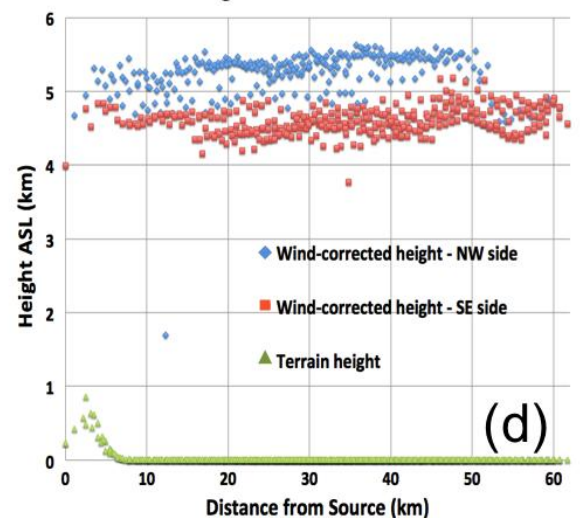

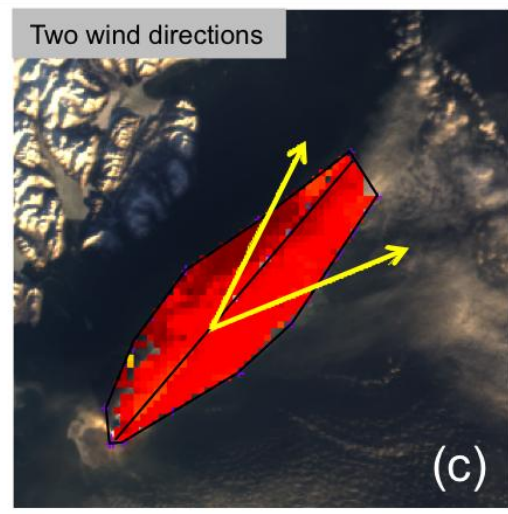

Retrieved Heights with Two Wind Directions

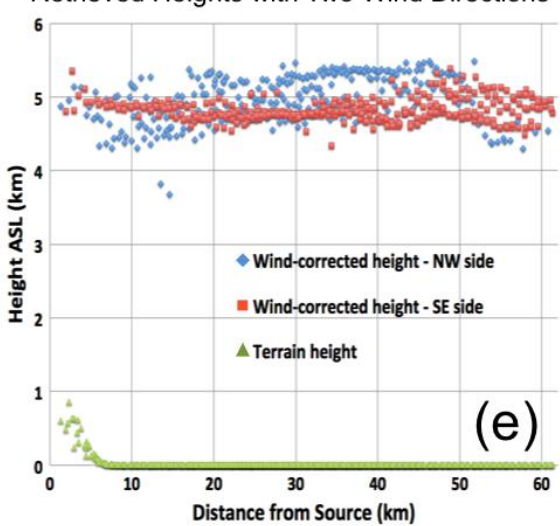




\section{Recent Examples}

In this section, we present a few examples of plume heights derived using MINX, illustrating a range of applications. Additional examples can be found on the NASA Earth Observatory web site [57]. There are roughly 13 years of MISR data from which to choose examples, with global coverage about once per week.

\subsection{Puyehue-Cordón Caulle Eruption}

On 5 June 2011, the Chilean volcano Puyehue-Cordón Caulle began erupting in a series of spectacular events that sent ash plumes more than $16 \mathrm{~km}$ into the stratosphere. Thick ash disrupted air traffic as far away as New Zealand and shut down many air carriers in South America. In southern Argentina, thick layers of ash covered towns and farms, endangering people and livestock, and forcing thousands of people to evacuate their homes. The ash plumes from Puyehue-Cordón Caulle were captured in more than 10 MISR overpasses, and those orbits were analyzed using MINX to determine the height and speed of transport of the ash.

Figure 14. The 11 June 2011, eruption of Puyehue-Cordon in Chile on orbit 61064, block 123: (a) Nadir image of eastward trending main plume, lower plume being blown toward the northeast, and ash-covered ground; (b) heights retrieved for the main plume reach $7 \mathrm{~km}$ and the secondary plume lies below $3 \mathrm{~km}$.
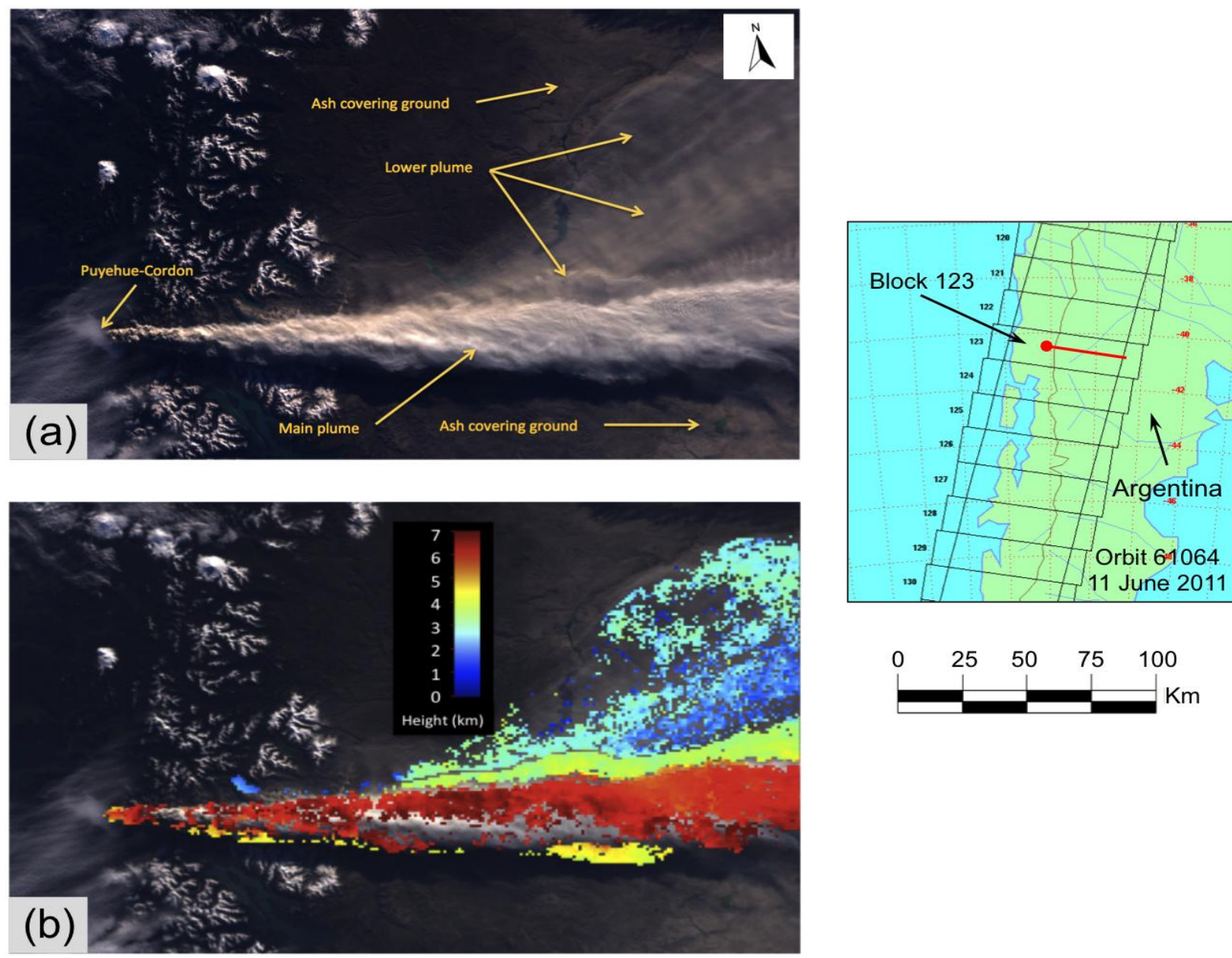
Figure 14a shows a $300 \mathrm{~km}$ wide MISR An (nadir) camera image of the ash ejected from Puyehue-Cordón Caulle on 11 June 2011. The main plume with retrieved heights around 6 to $7 \mathrm{~km}$, colored red in Figure 14b, is optically dense and narrow and travels eastward. A secondary plume with lower optical thickness and at much lower elevation than the main plume is colored blue to blue-green in Figure 14b, and is carried toward the northeast. A third, intermediate ash layer is wider than and below the main plume, has retrieved altitudes between 4 and $5 \mathrm{~km}$, and is identified by the yellow color. The gray terrain around the plumes is covered with ash from previous eruptive events. This illustrates some of the structural complexity that can be extracted from MISR data using MINX.

\subsection{Wallow Fire}

The image in Figure 15a shows the Wallow Fire in eastern Arizona that burned over 1,200 $\mathrm{km}^{2}$ and was one of the largest fires in Arizona history. The data shown were acquired mid-morning on 7 June 2011. The green pine forests of the White Mountains stand out against the lighter desert background. At least 10 bluish-colored smoke plumes from individual hot spots can be seen rising from the forests and being blown toward the upper right (northeast). The fires occur at the margins of dark areas that represent burn scars. In this image, the windblown smoke extends into New Mexico.

Figure 15. The Wallow fire in Arizona on 7 June 2011, on MISR orbit 61008, blocks 62-64:

(a) Nadir image of multiple smoke plumes from hot spots around dark burn scars;

(b) wind-corrected heights retrieved using the new blue-band and extra-large matcher template options in version 2.0 of MINX. Smoke reached a height of more than $5 \mathrm{~km}$ above-sea-level. Terrain heights in this region are about $2.5 \mathrm{~km}$.
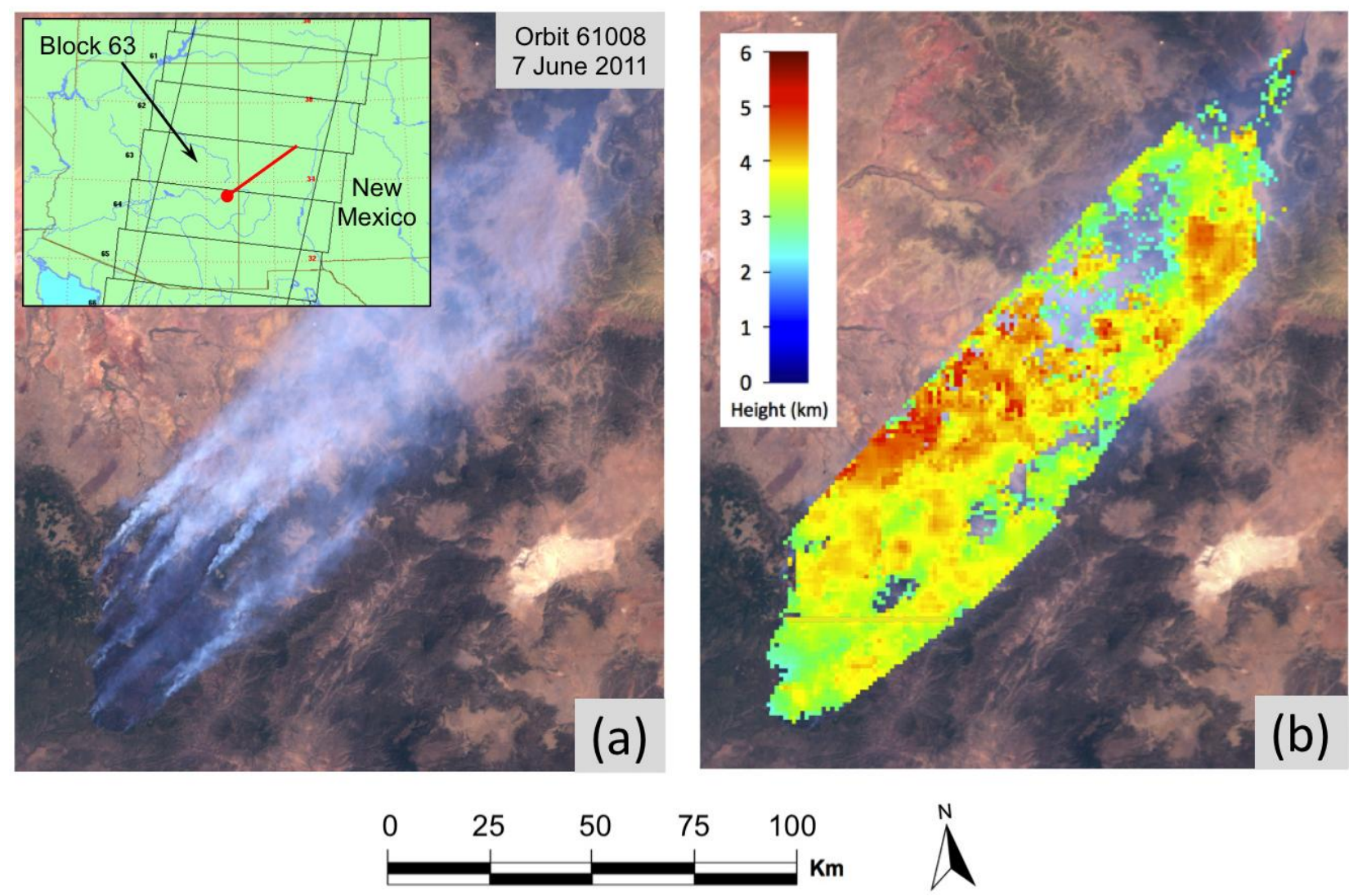
Figure 15b shows a map of the smoke heights retrieved using the MISR blue-band and the Extra-large matcher template. Terrain heights average about 2,500 $\mathrm{m}$ in this part of Arizona, so the smoke reaches a maximum height of $3 \mathrm{~km}$ above the terrain. Individual plumes can be distinguished in the height map, but their detail is smeared because of the large template used for matching. Equivalent analysis of this scene using the MISR red band produced much poorer results, mainly due to the brightness of the underlying terrain at this wavelength. The combination of plume heights from MISR and radiative energy flux from coincident MODIS-Terra 4 micron channel "hot spot" observations (e.g., Figure 1) [47,48] can be used to study the thermodynamics of smoke plume injection height $[13,26]$.

Figure 16. Dust over the Red Sea on MISR orbit 56371, block 75-76, from 24 July 2010: (a) MISR nadir image of arcuate plumes originating from dry stream beds in the Nubian desert of eastern Sudan; (b) sand is lofted very rapidly near the source and drops to near sea level; (c) the MINX retrieval shows that dust reaches a height of almost $1.5 \mathrm{~km}$ within 5-10 km of the source and drops to less than $0.5 \mathrm{~km}$ within about $170 \mathrm{~km}$; (d) MINX-derived total wind speed reaches $30 \mathrm{~m} \cdot \mathrm{s}^{-1}$.
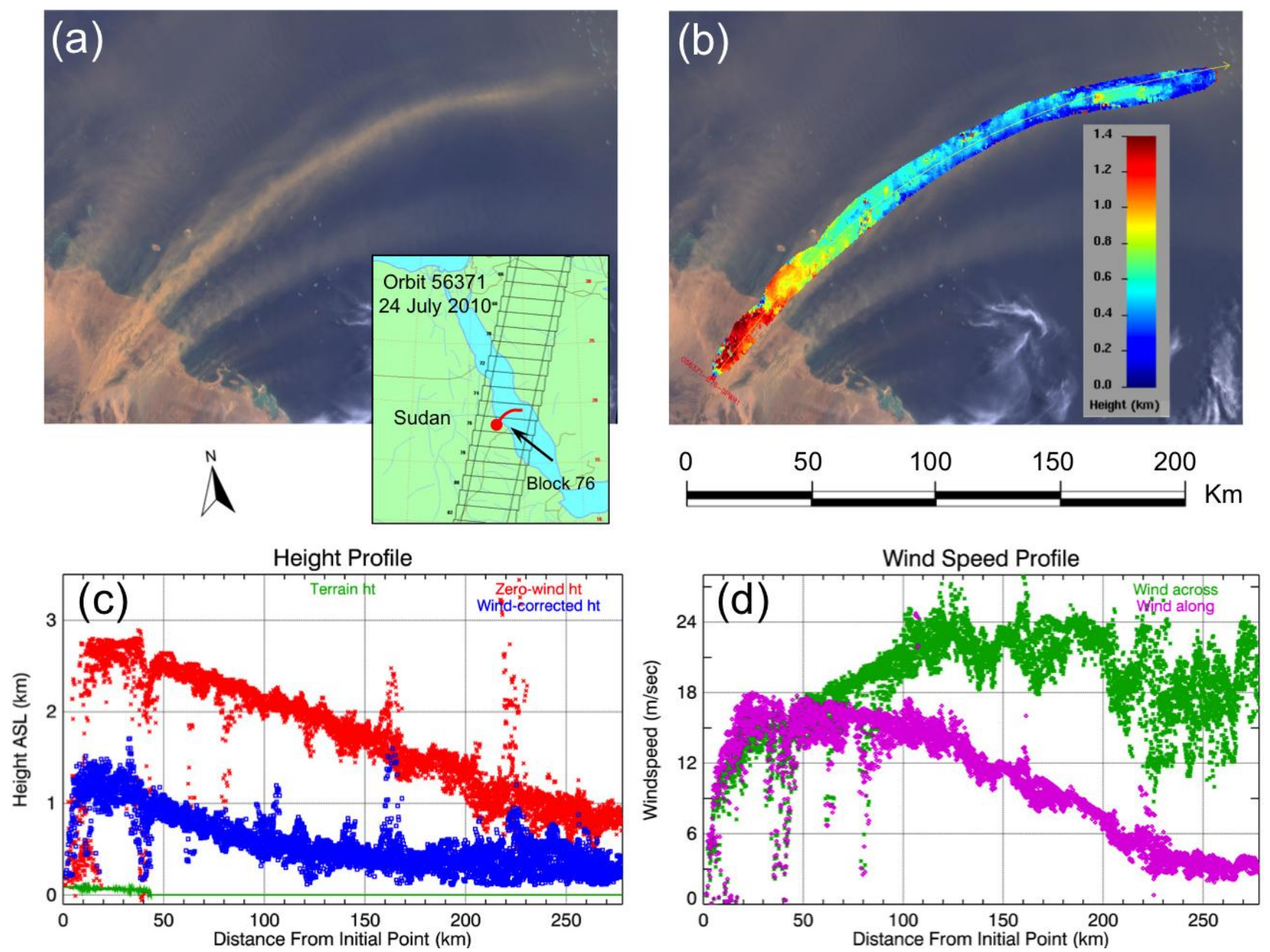

\subsection{Red Sea Dust}

On 24 July 2010, $20 \mathrm{~m} \cdot \mathrm{s}^{-1}$ onshore winds lofted large plumes of dust from dry riverbeds along the Red Sea coast of Sudan to elevations of almost $1.5 \mathrm{~km}$. The MISR image in Figure 16a shows the largest plume, extending for $270 \mathrm{~km}$ and approaching within $70 \mathrm{~km}$ of the Arabian Peninsula. Figure 16b,c 
shows MINX wind-corrected heights for the core of the plume in map view and in profile for this plume, respectively. In order to improve retrieval coverage and provide smoother results for this example, the smallest sample size and the largest matcher template were used during digitizing. Because the plume lies over both land and water, a MINX feature that allows automatic selection of blue-band retrievals over land and red-band retrievals over water could have been employed. However, in this case, the red-band produces better results over land due to the color and optical density of the dust.

The wind-corrected height profile in Figure 16c shows the dust rising very rapidly from the source area and reaching its maximum height within 5-10 km downwind. It lingers at this height until reaching the seacoast $40 \mathrm{~km}$ from the origin of the profile. Then the plume begins to settle until it sits within a few hundred meters above the water surface at the $170 \mathrm{~km}$ mark. The rapid rise over land and persistence of the plume at height may be due to thermal upwelling of air heated by sand. The decline in heights offshore could reflect the boundary layer height, which is generally much higher over desert than adjacent water during the daytime.

Figure 16d shows that total wind speed, which is the vector sum of the along-track and across-track wind speeds, increases with distance from the source, reaching its maximum of about $30 \mathrm{~m} \cdot \mathrm{s}^{-1} 100 \mathrm{~km}$ downwind. Note that the ratio of across-track wind to along-track wind is determined by the wind direction selected in the digitization process. Since this direction varies along the plume, the ratio of wind speeds varies to match it, and the wind-correction applied to retrieved heights varies as well.

\subsection{A Pyrocumulonimbus Cloud over the Silver Fire}

The spring of 2013 saw severe to extreme drought conditions in the Western United States. This led to a number of destructive wildfires in the Colorado and New Mexico, including the Silver Fire that was ignited by a lighting strike on 7 June 2013. Figure 17a shows the Silver Fire as it appeared in the MISR An (nadir) camera on 12 June 2013 at 18:09 UTC (12:09 pm local time). The bright white feature located in the lower right of the image is a pyrocumulonimbus (pyroCb) cloud, which is caused by intense heating of the air by the fire itself leading to rapid upward motion of the air until the point where condensation occurs. The subsequent release of latent heat from condensation leads to intense vertical development that can even penetrate into the stratosphere [58]. The dramatic difference in height between the pyroCb cloud and the associated smoke plume is clearly evident in Figure 17b,c. The plume was digitized with a wind direction parallel to the long axis of the smoke plume, extending from the fire source in the lower right to the upper left of the image. It is important to note that this wind direction may not be appropriate for the top of the pyroCb due to the possible presence of atmospheric wind shear. Even so, Figure 12c shows that the pyroCb reaches an altitude of almost $12 \mathrm{~km}$ above sea level (ASL), compared to the surrounding smoke that reaches only about $7 \mathrm{~km}$ in the vicinity of the pyroCb. An important advantage of MINX compared with common radiance-based passive remote sensing techniques is that the stereo retrievals are insensitive to the presence of temperature inversions that occur both at the top of the troposphere/bottom of the stratosphere, as well as near the poles and in the stratocumulus cloud regions of the world [36]. 
Figure 17. Pyrocumulonimbus (pyroCb) cloud associated with the Silver Fire in New Mexico on MISR orbit 71726, block 63-64, from 12 July 2013: (a) MISR nadir RGB image showing the smoke plume in gray colors and the pyroCb in bright white; (b) MINX height retrievals showing that the pyroCb is much higher than the surrounding smoke; (c) MINX height retrieval profiles showing the dramatic difference in the heights which reach 11-12 km ASL for the pyroCb, but only 6-7 km ASL for smoke in the vicinity.
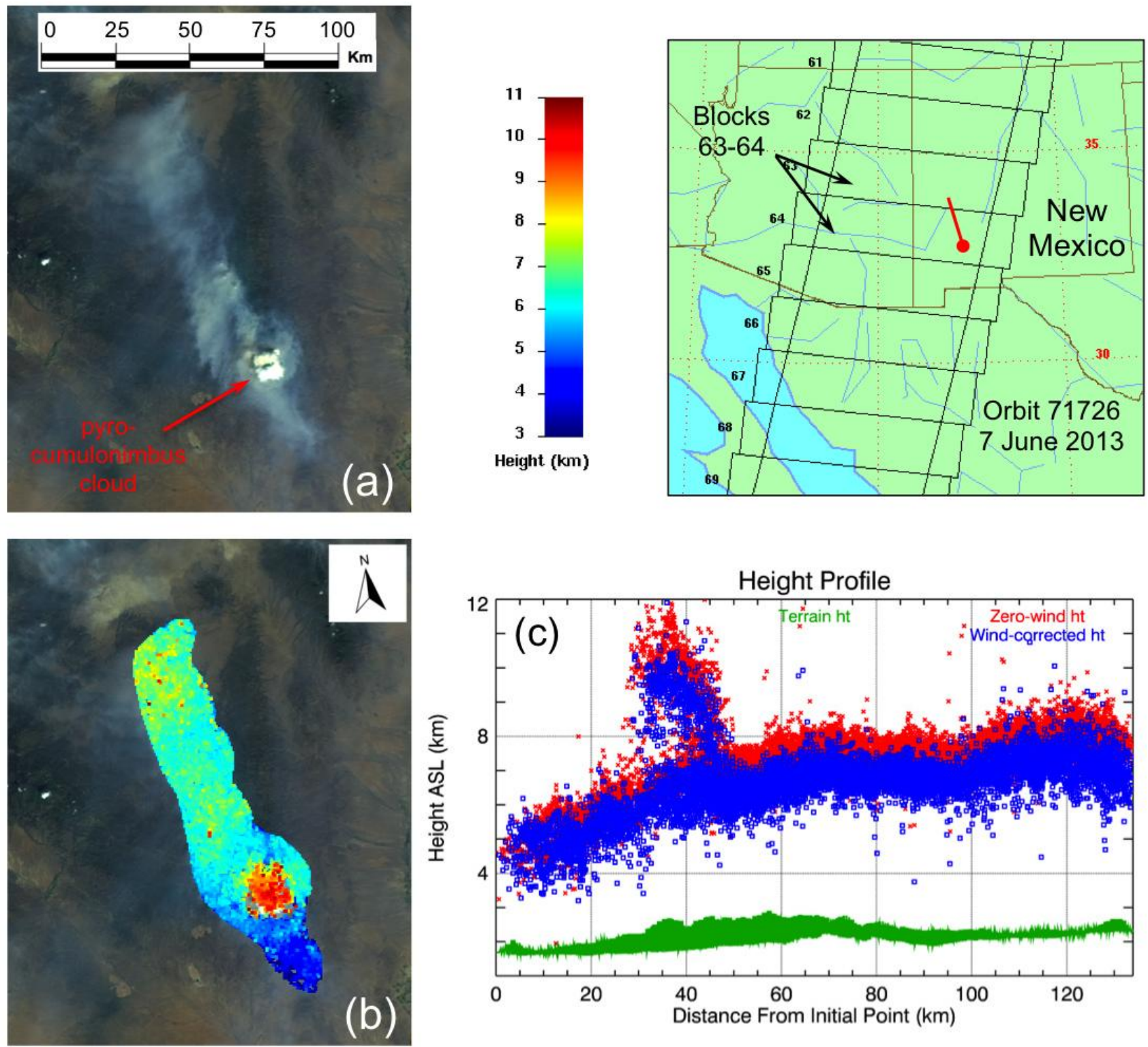

\section{Conclusion}

MINX is a unique tool that is able to retrieve heights and winds at horizontal intervals as small as $550 \mathrm{~m}$ and with vertical precision of about $200 \mathrm{~m}$ under good conditions using MISR radiance observations acquired at 275 and 1,100 m horizontal resolution. This precision can be obtained because of three important features of the program: (1) it relies on interaction with a user to supply wind directions that reduce the number of unknowns in the retrieval problem from three to two; (2) sub-pixel image matching using normalized cross-correlation improves the retrieval precision; and (3) averaging retrieval results from multiple camera pairs reduces noise and improves the precision further. MINX 
complements the MISR operational stereo-height products, which report heights for the entire MISR global data record, but with lower precision and lower sensitivity to optically thin features. A growing database of wildfire smoke and volcanic plume height maps and winds digitized using MINX, along with documentation, is available at the "MISR Plume Height Project" website [27].

\section{Acknowledgment}

The authors thank D. J. Diner, principal investigator for the MISR investigation, for his support of the Plume Height Project. We also thank V. Jovanovic for leading the development of the georectified MISR image products that make this project possible. Finally, we thank E. G. Hansen, MISR project manager, for his support of MINX development. This research was carried out at the Jet Propulsion Laboratory, California Institute of Technology, under contract with NASA and at the NASA Goddard Space Flight Center. The work of R. Kahn is also supported by the NASA Earth Sciences Atmospheric Composition Modeling and Analysis Program under R. Eckman.

The MISR data used in this paper were obtained from the NASA Langley Research Center Atmospheric Science Data Center. Development of the MINX software is supported by the NASA Earth Observing System's MISR Project. Applications are supported in part by the MISR Project, as well as by the NASA Climate and Radiation and Atmospheric Composition Research and Analysis programs.

\section{Conflicts of Interest}

The authors declare no conflict of interest.

\section{References}

1. Yu, H.; Kaufman, Y.J.; Chin, M.; Feingold, G.; Remer, L.A.; Anderson, T.L.; Balkanski, Y.; Bellouin, N.; Boucher, O.; Christopher, S.; et al. A review of measurement-based assessments of the aerosol direct radiative effect and forcing. Atmos. Chem. Phys. 2006, 6, 613-666.

2. Schulz, M.; Textor, C.; Kinne, S.; Balkanski, Y.; Bauer, S.; Berntsen, T.; Berglen, T.; Boucher, O.; Dentener, F.; Guibert, S.; et al. Radiative forcing by aerosols as derived from the AeroCom present-day and pre-industrial simulations. Atmos. Chem. Phys. 2006, 6, 5225-5246.

3. Pósfai, M.; Buseck, P.R. Nature and climate effects of individual tropospheric aerosol particles. Annu. Rev. Earth Planet. Sci. 2010, 38, 17-43.

4. Liu, J.; Mauzerall, D.L.; Horowitz, L.W. Evaluating inter-continental transport of fine aerosols: (2) Global health impact. Atmos. Environ. 2009, 43, 4339-4347.

5. Casadevall, T.J. The 1989-1990 eruption of Redoubt Volcano, Alaska: Impacts on aircraft operations. J. Volcanol. Geotherm. Res. 1994, 62, 301-316.

6. Kahn, R.A.; Chen, Y.C.; Nelson, D.L.; Leung, F.-Y.; Li, Q.; Diner, D.J.; Logan, J.A. Wildfire smoke injection heights-Two perspectives from space. Geophys. Res. Lett. 2008, 35, L04809.

7. Chen, Y.; Li, Q.; Randerson, J.T.; Lyons, E.A.; Kahn, R.A.; Nelson, D.L.; Diner, D.J. The sensitivity of $\mathrm{CO}$ and aerosol transport to the temporal and vertical distribution of North American boreal fire emissions. Atmos. Chem. Phys. 2009, 9, 6559-6580.

8. Haywood, J.M.; Ramaswamy, V. Global sensitivity studies of the direct radiative forcing due to anthropogenic sulfate and black carbon aerosols. J. Geophys. Res. 1998, 103, 6043-6058. 
9. Flanner, M.G.; Zender, C.S.; Randerson, J.T.; Rasch, P.J. Present-day climate forcing and response from black carbon in snow. J. Geophys. Res. 2007, 112, D11202.

10. Ocko, I.B.; Ramaswamy, V.; Ginoux, P.; Ming, Y.; Horowitz, L.W. Sensitivity of scattering and absorbing aerosol direct radiative forcing to physical climate factors. J. Geophys. Res. 2012, 117, D20203.

11. Hasler, A.F. Stereographic observations from geosynchronous satellites: An important new tool for the atmospheric sciences. Bull. Am. Meteorol. Soc. 1981, 62, 194-212.

12. Diner, D.J.; Beckert, J.C.; Reilly, T.H.; Bruegge, C.J.; Conel, J.E.; Kahn, R.A.; Martonchik, J.V.; Ackerman, T.P.; Davies, R.; Gerstl, S.A.W.; et al. Multi-angle Imaging SpectroRadiometer (MISR) instrument description and experiment overview. IEEE Trans. Geosci. Remote Sens. 1998, 36, 1072-1087.

13. Kahn, R.A.; Li, W.-H.; Moroney, C.; Diner, D.J.; Martonchik, J.V.; Fishbein, E. Aerosol source plume physical characteristics from space-based multiangle imaging. J. Geophys. Res. 2007, 112, D11205.

14. Horváth, Á.; Davies, R. Feasibility and error analysis of cloud motion wind extraction from near-simultaneous multiangle MISR measurements. J. Atmos. Ocean. Technol. 2001, 18, 591-608.

15. Zong, J.; Davies, R.; Muller, J.-P.; Diner, D.J. Photogrammetric retrieval of cloud advection and top height from the Multi-angle Imaging Spectroradiometer (MISR). Photogramm. Eng. Remote Sens. 2002, 68, 821-829.

16. Moroney, C.; Davies, R.; Muller, J.-P. Operational retrieval of cloud-top heights using MISR data. IEEE Trans. Geosci. Remote Sens. 2002, 40, 1532-1540.

17. Muller, J.-P.; Mandanayake, A.; Moroney, C.; Davies, R.; Diner, D.J.; Paradise, S. MISR stereoscopic image matchers: Techniques and results. IEEE Trans. Geosci. Remote Sens. 2002, 40, $1547-1559$.

18. Winker, D.M.; Vaughan, M.A.; Omar, A.; Hu, Y.; Powell, K.A.; Liu, Z.; Hunt, W.H.; Young, S.A. Overview of the CALIPSO mission and CALIOP data processing algorithms. J. Atmos. Ocean. Technol. 2009, 26, 2310-2323.

19. Wu, D.L.; Chae, J.H.; Lambert, A.; Zhang, F.F. Characteristics of CALIOP attenuated backscatter noise: Implication for cloud/aerosol detection. Atmos. Chem. Phys. 2011, 11, 2641-2654.

20. Holz, R.E.; Ackerman, S.A.; Nagle, F.W.; Frey, R.; Dutcher, S.; Kuehn, R.E.; Vaughan, M.A.; Baum, B. Global Moderate Resolution Imaging Spectroradiometer (MODIS) cloud detection and height evaluation using CALIOP. J. Geophys. Res. 2008, 113, D00A19.

21. Mazzoni, D.; Logan, J.A.; Diner, D.; Kahn, R.; Tong, L.; Li, Q. A data-mining approach to associating MISR smoke plume heights with MODIS fire measurements. Remote Sens. Environ. 2007, 107, 138-148.

22. Marey, H.S.; Gille, J.C.; El-Askary, H.M.; Shalaby, E.A.; El-Raey, M.E. Study of the formation of the black cloud and its dynamics over Cairo, Egypt, using MODIS and MISR sensors. J. Geophys. Res. 2010, 115, D21206.

23. Mims, S.R.; Kahn, R.A.; Moroney, C.M.; Gaitley, B.J.; Nelson, D.L.; Garay, M.J. MISR stereo heights of grassland fire smoke plumes in Australia. IEEE Trans. Geosci. Remote Sens. 2010, 48, $25-35$. 
24. Tosca, M.G.; Randerson, J.T.; Zender, C.S.; Nelson, D.L.; Diner, D.J.; Logan, J.A. Dynamics of fire plumes and smoke clouds associated with peat and deforestation fires in Indonesia. J. Geophys. Res. 2011, 116, D08209.

25. Val Martin, M.; Logan, J.A.; Kahn, R.A.; Leung, F.-Y.; Nelson, D.L.; Diner, D.J. Smoke injection heights from fires in North America: Analysis of 5 years of satellite observations. Atmos. Chem. Phys. 2010, 10, 1491-1510.

26. Val Martin, M.; Kahn, R.A.; Logan, J.A.; Paugam, R.; Wooster, M.; Ichoku, C. Space-based observational constraints for 1-D fire smoke plume-rise models. J. Geophys. Res. 2012, 117, D22204.

27. MISR Plume Height Project. Available online: http://www-misr.jpl.nasa.gov/getData/accessData/ MisrMinxPlumes/ (accessed on 12 September 2013).

28. Scollo, S.; Folch, A.; Coltelli, M.; Realmuto, V.J. Three-dimensional volcanic aerosol dispersal: A comparison between Multiangle Imaging Spectroradiometer (MISR) data and numerical simulations. J. Geophys. Res. 2010, 115, D24210.

29. Heinold, B.; Tegen, I.; Wolke, R.; Ansmann, A.; Mattis, I.; Minikin, A.; Schumann, U.; Weinzierl, B. Simulations of the 2010 Eyjafjallajökull volcanic ash dispersal over Europe using COSMO-MUSCAT. Atmos. Environ. 2012, 48, 195-204.

30. Scollo, S.; Kahn, R.A.; Nelson, D.L.; Coltelli, M.; Diner, D.J.; Garay, M.J.; Realmuto, V.J. MISR observations of Etna volcanic plumes. J. Geophys. Res. 2012, 117, D06210.

31. Kahn, R.S.; Limbacher, J.A. Eyjafjalljökull volcano plume particle-type characterization from space-based multi-angle imaging. Atmos. Chem. Phys. 2012, 12, 9459-9477.

32. Ekstrand, A.L.; Webley, P.W.; Garay, M.J.; Dehn, J.; Prakash, A.; Nelson, D.L.; Dean, K.G.; Steensen, T. A multi-sensor plume height analysis of the 2009 redoubt eruption. J. Volcanol. Geotherm. Res. 2013, 259, 170-184.

33. Naud, C.; Muller, J.-P.; Clothiaux, E.E. Comparison of cloud top heights derived from MISR stereo and MODIS CO 2 -slicing. Geophys. Res. Lett. 2002, doi: 10.1029/2002GL015460.

34. Naud, C.M.; Muller, J.-P.; Clothiaux, E.E.; Baum, B.A.; Menzel, W.P. Intercomparison of multiple years of MODIS, MISR and radar cloud-top heights. Ann. Geophys. 2005, 23, 2415-2424.

35. Marchand, R.T.; Ackerman, T.P.; Moroney, C. An assessment of Multiangle Imaging Spectroradiometer (MISR) stereo-derived cloud top heights and cloud top winds using ground-based radar, lidar, and microwave radiometers. J. Geophys. Res. 2007, 112, D06204.

36. Garay, M.J.; de Szoeke, S.P.; Moroney, C.M. Comparison of marine stratocumulus cloud top heights in the southeastern Pacific retrieved from satellites with coincident ship-based observations. J. Geophys. Res. 2008, 113, D18204.

37. Diner, D.J.; Beckert, J.C.; Bothwell, G.W.; Rodriguez, J.I. Performance of the MISR instrument during its first 20 months in Earth orbit. IEEE Trans. Geosci. Remote Sens. 2001, 40, 1449-1466.

38. Bothwell, G.W.; Hansen, E.G.; Vargo, R.E.; Miller, K.C. The Multi-angle Imaging SpectroRadiometer science data system, its products, tools, and performance. IEEE Trans. Geosci. Remote Sens. 2002, 40, 1467-1476.

39. MISR Data and Information. Available online: https://eosweb.larc.nasa.gov/project/misr/ misr_table (accessed on 12 September 2013). 
40. NASA's Earth Observing System. Available online: http://eospso.gsfc.nasa.gov/atbd-category/45 (accessed on 12 September 2013).

41. MISR Data Products Specifications. Available online: https://eosweb.larc.nasa.gov/project/misr/ dps (accessed on 12 September 2013).

42. Jovanovic, V.M.; Smyth, M.M.; Zong, J.; Ando, R.; Bothwell, G.W. MISR photogrammetric data reduction for geophysical retrievals. IEEE Trans. Geosci. Remote Sens. 1998, 36, 1290-1301.

43. Davies, R.; Horváth, Á.; Moroney, C.; Zhang, B.; Zhu, Y. Cloud motion vectors from MISR using sub-pixel enhancements. Remote Sens. Environ. 2007, 107, 194-199.

44. EXELIS Visual Data Solutions. Available online: http://www.exelisvis.com/ProductsServices/ IDL.aspx (accessed on 12 September 2013).

45. Open Channel Foundation: MINX-MISR Interactive eXplorer. Available online: http://www.openchannelsoftware.com/projects/MINX (accessed on 12 September 2013).

46. Mazzoni, D.; Garay, M.J.; Davies, R.; Nelson, D. An operational MISR pixel classifier using support vector machines. Remote Sens. Environ. 2007, 107, 149-158.

47. Justice, C.O.; Giglio, L.; Korontzi, S.; Owens, J.; Morisette, J.T.; Roy, D.; Descloitres, J.; Alleaume, S.; Petitcolin, F.; Kaufman, Y. The MODIS fire products. Remote Sens. Environ. 2002, 83, 244-262.

48. Giglio, L.; Descloitres, J.; Justice, C.O.; Kaufman, Y.J. An enhanced contextual fire detection algorithm for MODIS. Remote Sens. Environ. 2003, 87, 273-282.

49. MINX PDF Documentation - 6 Files. Available online: https://www.openchannelsoftware.com/ orders/index.php?group_id=366 (accessed on 12 September 2013).

50. Nelson, D.L.; Chen, Y.; Kahn, R.A.; Diner, D.J.; Mazzoni, D. Example applications of the MISR INteractive eXplorer (MINX) software tool to wildfire smoke plume analyses. Proc. SPIE 2008, 7089, 708909.

51. Jovanovic, V.; Moroney, C.; Nelson, D. Multi-angle geometric processing for globally geo-located and co-registered MISR image data. Remote Sens. Environ. 2007, 107, $22-32$.

52. Jovanovic, V.M.; Bull, M.A.; Smyth, M.M.; Zong, J. MISR in-flight camera geometric model calibration and georectification performance. IEEE Trans. Geosci. Remote Sens. 2002, 40, $1512-1519$.

53. Moroney, C.; Horváth, Á.; Davies, R. Use of stereo-matching to coregister multiangle data from MISR. IEEE Trans. Geosci. Remote Sens. 2002, 40, 1541-1546.

54. Todd, M.C.; Washington, R.; Martins, J.V.; Dubovik, O.; Lizcano, G.; M'Bainayel, S.; Engelstaedter, S. Mineral dust emission from the Bodélé Depression, northern Chad, during BoDEx 2005. J. Geophys. Res. 2007, 112, D06207.

55. Koren, I.; Kaufman, Y.J. Direct wind measurements of Saharan dust events from Terra and Aqua satellites. Geophys. Res. Lett. 2004, 31, L06122.

56. Ernst, G.J.; Davis, J.P.; Sparks, R.S. Bifurcation of volcanic plumes in a crosswind. Bull. Volcanol. 1994, 56, 159-169.

57. NASA Earth Observatory. Available online: http://earthobservatory.nasa.gov (accessed on 12 September 2013). 
58. Fromm, M.; Lindsey, D.T.; Servranckx, R.; Yue, G.; Trickl, T.; Sica, R.; Doucet, P.; Godin-Beekmann, S. The untold story of pyrocumulonimbus. Bull. Am. Meteorol. Soc. 2010, 91, 1193-1209.

(C) 2013 by the authors; licensee MDPI, Basel, Switzerland. This article is an open access article distributed under the terms and conditions of the Creative Commons Attribution license (http://creativecommons.org/licenses/by/3.0/). 